\title{
Experimental techniques for the calibration of lidar depolarization channels in EARLINET
}

\author{
Livio Belegante ${ }^{1}$, Juan Antonio Bravo-Aranda ${ }^{2,3}$, Volker Freudenthaler ${ }^{4}$, Doina Nicolae ${ }^{1}$, Anca Nemuc ${ }^{1}$, Dragos Ene ${ }^{1}$, \\ Lucas Alados-Arboledas ${ }^{2,3}$, Aldo Amodeo ${ }^{5}$, Gelsomina Pappalardo ${ }^{5}$, Giuseppe D'Amico ${ }^{5}$, Francesco Amato ${ }^{5}$, \\ Ronny Engelmann ${ }^{6}$, Holger Baars ${ }^{6}$, Ulla Wandinger ${ }^{6}$, Alexandros Papayannis ${ }^{7}$, Panos Kokkalis ${ }^{7}$, and \\ Sérgio N. Pereira ${ }^{8}$ \\ ${ }^{1}$ National Institute of Research and Development for Optoelectronics, 409 Atomistilor Str, Magurele, Romania \\ ${ }^{2}$ Andalusian Institute for Earth System Research, Granada, Spain \\ ${ }^{3}$ Department of Applied Physcis, University of Granada, Granada, Spain \\ ${ }^{4}$ Meteorological Institute, Ludwig-Maximilians-Universitat, Theresienstr. 37, 80333 Munich, Germany \\ ${ }^{5}$ Istituto di Metodologie per l'Analisi Ambientale CNR-IMAA, C.da S. Loja, Tito Scalo, Potenza 85050, Italy \\ ${ }^{6}$ Leibniz Institute for Tropospheric Research, Permoserstr. 15, 04318 Leipzig, Germany \\ ${ }^{7}$ National Technical University of Athens (NTUA), Physics Department, Heroon Polytechniou 9, 15780 Zografou, \\ Athens, Greece \\ ${ }^{8}$ Evora Geophysics Center, Rua Romao Ramalho 59, 7000, Evora, Portugal
}

Correspondence: Juan Antonio Bravo-Aranda (jabravo@ugr.es)

Received: 2 May 2017 - Discussion started: 27 June 2017

Revised: 25 October 2017 - Accepted: 31 October 2017 - Published: 26 February 2018

\begin{abstract}
Particle depolarization ratio retrieved from lidar measurements are commonly used for aerosol-typing studies, microphysical inversion, or mass concentration retrievals. The particle depolarization ratio is one of the primary parameters that can differentiate several major aerosol components but only if the measurements are accurate enough. The accuracy related to the retrieval of particle depolarization ratios is the driving factor for assessing and improving the uncertainties of the depolarization products. This paper presents different depolarization calibration procedures used to improve the quality of the depolarization data. The results illustrate a significant improvement of the depolarization lidar products for all the selected lidar stations that have implemented depolarization calibration procedures. The calibrated volume and particle depolarization profiles at $532 \mathrm{~nm}$ show values that fall within a range that is generally accepted in the literature.
\end{abstract}

\section{Introduction}

Uncertainties related to the influence of anthropogenic activities on the Earth's energy budget and climate change have led to a real interest regarding the aerosols direct and indirect radiative effects (Stocker et al., 2013). Measurements of vertically resolved aerosol optical properties (as the ones taken by lidar systems) try to reduce these uncertainties. These systems are laser-based instruments able to provide quantitative information on aerosol layering and their properties (Measures et al., 1992). The principle is based on the detection of backscattered light that results from the interaction of the emitted laser light with the atmospheric constituents. Figure 1 shows the main components of a lidar system with polarizing capabilities. The emitted laser light is oriented towards the atmosphere by means of the emission optics. After the emitted light interacts with atmospheric constituents, the backscattered light is collected by a telescope and directed to the wavelength separation unit (WSU - also named the receiving optics unit for this study), polarizing beam splitter (PBS) and photomultipliers (PMTs). The receiving optics (mirrors, lenses and dichroic filters), the PBS and the PMTs will be treated as distinct units, since the effects of each unit 


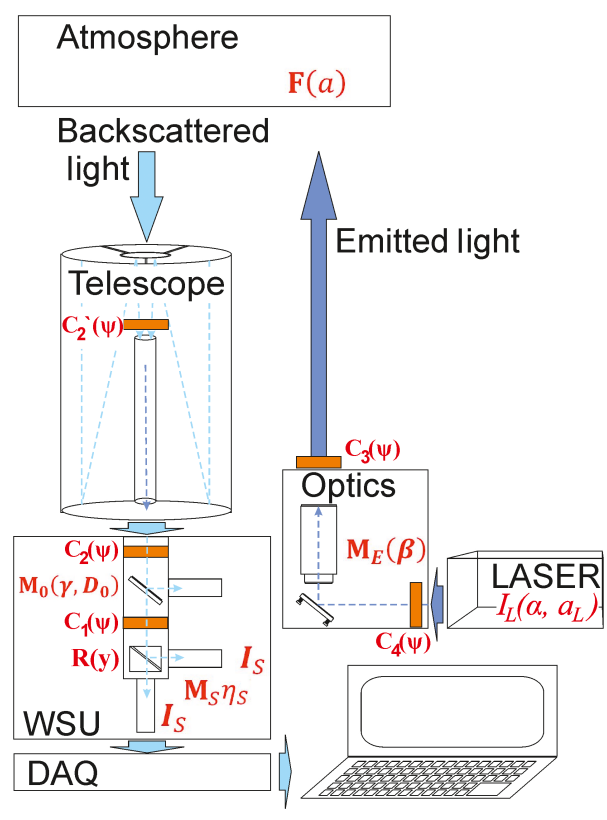

Figure 1. Schematics of a lidar system. Emission block is the laser and the emission optics; receiving block is the telescope, wavelength separation unit (WSU) and data acquisition (DAQ) block. Mueller-Stokes notations (red) for specific optical components used later in the study. Possible positions of the calibration units (orange) with respect to the optical layout.

alters the depolarization profiles from different perspectives. The collected laser light contains information about the optical properties of the atmospheric components and consequently on their size, shape and composition. Methods to retrieve these properties from elastic backscatter, Raman, multiwavelength and depolarization lidars are already described in detail in the literature (Fernald et al., 1972; Klett et al., 1981, 1985; Kovalev and Eichinger, 2004). According to their application, lidar systems have different configurations, channel combinations and geometries. For atmospheric studies, the configuration of a lidar system narrows down to several types and optical layouts.

A major breakthrough in atmospheric studies is the development of global lidar networks that are able to provide systematic lidar data flow with a large temporal and spatial coverage (Earlinet, 2014a). The European Aerosol Research Lidar Network data (EARLINET) (Pappalardo et al., 2013, 2014) are relevant for climatology, regional and largescale model assessment but also for special events such as Saharan dust outbreaks, transport of smoke plumes or volcanic ash over Europe (Earlinet, 2014b, d, e), (Papayannis et al., 2008; Ansmann et al., 2009; Ansmann and Bosenberg, 2003; Nicolae et al., 2013; Mona et al., 2012; Timofte et al., 2015; Mortier et al., 2013). The multiwavelength depolarization Raman lidar systems used in EARLINET ( 3 backscatter +2 Raman +1 depolarization: $3 \beta+2 \alpha+\delta$ lidar systems - Mona et al., 2012) are capable of providing an extended set of optical parameters for aerosol characterization by assuring the quality of the products through internal data quality procedures. For depolarization studies, most of the lidar systems are designed to independently measure two channels corresponding to the parallel and perpendicular polarizing-plane with respect to the polarizing plane of the emitted light.

Recent atmospheric studies based on remote sensing data have been dedicated to aerosol typing, microphysical inversion and aerosol mass concentration retrievals. Since for these studies the most reliable optical parameters should be sensitive to the aerosol un-isotropy (e.g., shape) (Hervo et al., 2012; Groß et al., 2015; Bravo-Aranda et al., 2013), the depolarization products obtained from lidar measurements proved to be essential, giving the opportunity to distinguish between spherical particles with low depolarization ratios and nonspherical particles with higher depolarization ratios (Gasteiger et al., 2014). Lidar measurements of particle linear depolarization ratio are often used to discriminate between low-depolarizing (e.g., urban aerosol) and highdepolarizing aerosols (e.g., dust), or liquid and ice clouds, requiring only a relative measurement of these parameters. At the present state, the uncertainties of these products are high for EARLINET lidars and any aerosol classification based on relative lidar depolarization profiles is challenging. For aerosol-typing and mass concentration studies, absolute values of particle linear depolarization ratio are needed. According to Petzold et al. (2010); Groß et al. (2013); Burton et al. (2012), the particle linear depolarization values characterizing several aerosol species (or mixtures of aerosols) are close to one another or overlap in some ranges: for pure dust, the particle depolarization value at $532 \mathrm{~nm}$ ranges from 0.30 to 0.39 and for dust mixtures from 0.1 to 0.3 . The same issue emerges when discriminating between biomass burning aerosol mixed with mineral dust and industrial pollution aerosol, with values around 0.1 to 0.2 for the first and 0.04 to 0.1 for the second (Janicka et al., 2017). Therefore, in order to discriminate between different types of particle, the uncertainty of the depolarization products must be reduced. Furthermore, in this paper we will show that without proper assessment of instrumental errors, the associated uncertainties are estimated to be over $10 \%$ for most lidar instruments presented in the study. Recent studies showed that even small deviations from ideal lidar optics can lead to large uncertainties of the retrieved depolarization products (Bravo-Aranda et al., 2016). Typically, the main source of uncertainty does not come from the detected signal noise but from systematic errors in the optical setup of the lidar systems (Freudenthaler et al., 2009; Freudenthaler, 2016; Alvarez et al., 2006; Snels et al., 2009; Biele et al., 2000; David, et al., 2012). One of the most efficient ways to measure the absolute value of depolarization parameters is by implementing hardware depolarization calibration methods.

This study aims to present the available techniques developed to calibrate the lidar depolarization channels in EARLINET (David, et al., 2012; Freudenthaler, 2016) with focus 
on one particular technique $\left(\Delta 90^{\circ}\right.$ calibration). This technique will be further used to assess the influence of lidar optics on depolarization products (i.e., the assessment of the receiving optics diattenuation parameter and the rotation of the plane of polarization of the laser around the light propagation axis with respect to the PBS) in order to reduce the corresponding uncertainties (Mattis et al., 2009).

The study also provides different experimental procedures for the assessment of several instrument parameters required to correct the lidar depolarization products, stressing the effects of these parameters on the depolarization products. A first assessment of the depolarization accuracy is also provided for selected lidar instruments. This study will be a useful reference for EARLINET operators and for those wishing to understand the data quality procedures of EARLINET depolarization measurements. The reader has the opportunity to follow the current calibration procedures used in EARLINET, starting from the theory and then following all required steps to reach the final calibrated data products.

The first part of the paper describes the theoretical background, architecture, methodology and a broad description of the available calibration procedures. New techniques used to retrieve the influence of different optical modules on depolarization products are presented and discussed. Techniques to assess and correct the rotation of the plane of polarization of the laser around the light propagation axis are also introduced.

Section 2 describes the theoretical background based on the Mueller-Stokes formalism, used as the basis for the entire study (David, et al., 2013; Freudenthaler, 2016). The methodology is given in Sect. 3 .

The second part of the paper shows results of calibrated and noncalibrated lidar depolarization profiles, several case studies from different lidar instruments in EARLINET, discussions and conclusions. Volume and particle linear depolarization ratios are presented, emphasizing the added value of calibrated depolarization channels, especially when quantitative information is required. Section 4 shows the results, and discussions and the conclusions are given in Sect. 5.

The practical approach of the paper is designed to present how depolarization calibration procedures are implemented. Most of the available literature is focused on the theoretical perspective of the topic and practical issues usually remain unresolved.

\section{Theoretical background}

The Mueller-Stokes formalism (Chipman, 2009; Ossikovski et al., 2010; Lu and Chipman, 1996) describing the lidar system setup (shown in Fig. 1) can be summarized by the following equation (Freudenthaler, 2016):

$$
\boldsymbol{I}_{\mathrm{S}}=\eta_{\mathrm{S}} \mathbf{M}_{\mathrm{S}}\left(D_{\mathrm{S}}\right) \mathbf{R}(y) \mathbf{M}_{\mathrm{O}}\left(\gamma, D_{\mathrm{O}}\right) \mathbf{F}(a) \mathbf{M}_{\mathrm{E}}(\beta) \boldsymbol{I}_{\mathrm{L}}\left(\alpha, a_{\mathrm{L}}\right),
$$
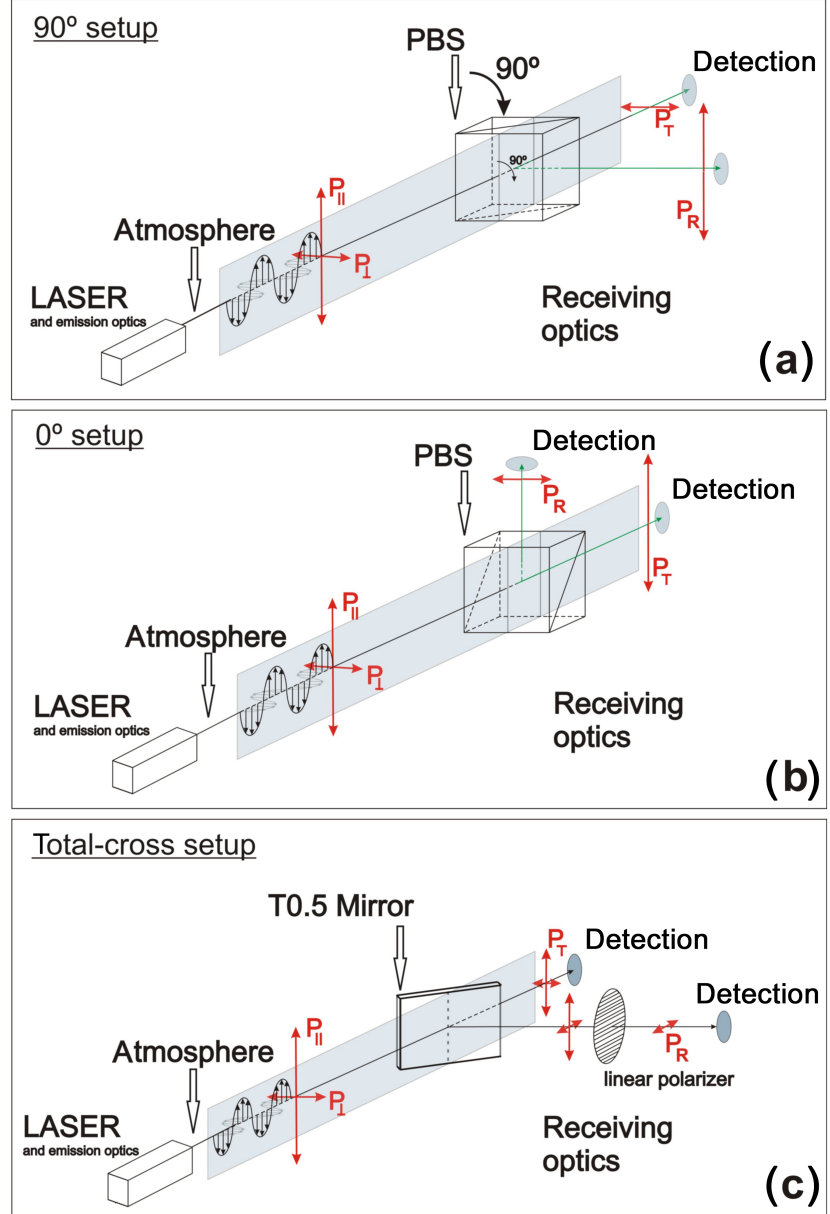

Figure 2. Detection setups (according to Freudenthaler et al., 2009). $P_{\perp}$ and $P_{\|}$are the collected components (parallel and cross). $P_{\mathrm{T}}$ and $P_{\mathrm{R}}$ are detected components of the collected radiation (with contribution from the receiving optics). (a) $90^{\circ}$ detection setup, (b) $0^{\circ}$ detection setup and (c) detection setup for PollyXT-type lidar systems. PBS is a polarizing beam splitter, T0.5 mirror is a 0.5 transmittance reflecting mirror.

where bold italic fonts are used for the Stokes vectors, bold for the Mueller matrices and italic for the scalar variables.

Mueller matrices and Stokes vectors: $\boldsymbol{I}_{\mathrm{L}}\left(\alpha, a_{\mathrm{L}}\right)$ is the Stokes vector of the light emitted by the laser, $\mathbf{M}_{\mathrm{E}}$ is the Mueller matrix of the emission block optics, $\mathbf{F}$ represents the Mueller matrix of the atmospheric scattering volume in backscattering direction, $\mathbf{M}_{\mathrm{O}}$ is the receiving optics matrix characterized by the receiving optics diattenuation parameter $D_{\mathrm{O}}, \mathbf{R}(y)$ is the rotation matrix, $\mathbf{M}_{\mathrm{S}}$ stands for both parts of the PBS, i.e., the transmitted (subscript T) and reflected (subscript R) channels, including additional polarizing elements after the PBS, and $\boldsymbol{I}_{\mathrm{S}}$ is the Stokes vector for the two detected channels (i.e., reflected $\boldsymbol{I}_{\mathrm{R}}$ and transmitted $\boldsymbol{I}_{\mathrm{T}}$ ) (see also Fig. 1) describing the polarization state of the measured channels. 
Scalar variables: $a_{\mathrm{L}}$ is the polarization parameter of the light beam leaving the laser (the laser beam polarization purity), $\alpha$ is the rotation of the plane of polarization of the laser around the propagation axis (also called laser rotation), $\beta$ is the rotation of the emitter optics around the propagation axis with respect to the PBS, $a$ is the polarization parameter of the atmospheric volume described later in more detail, $D_{\mathrm{O}}$ is the diattenuation parameter, $\gamma$ is the rotation of the receiver optics around the propagation axis with respect to the PBS, $y$ describes the optical setup type (see Fig. 2a-b) and $D_{\mathrm{S}}$ is the PBS diattenuation parameter. The incident plane of the PBS is taken as the reference plane for all rotation angles around the optical axis. $\eta$ represents the calibration factor that accounts only for the electronic amplification and the optical diattenuation of the two polarizing channels.

In order to have a complete characterization of the lidar optics, the contribution of all latter parameters must be accounted for. The technological solutions for mounting the receiving optics and the PBS are based on high-precision optical mounts for all the considered lidar setups. These implementations ensure high accuracy and minimization of any rotation misalignment of the optics. The analyzed EARLINET lidars have the $\gamma$ and $\beta$ angles lower than $0.5^{\circ}$ as indicated by Bravo-Aranda et al. (2016). Since the larger uncertainties are expected for $D_{\mathrm{O}}$ and $\alpha$, we neglect the effect of the $\gamma$ and $\beta$ angles on these lidar systems.

A significant simplification comes from the $v$ component of the emitted Stokes vector $(i, q, u, v)$ (Chipman, 2009; $\mathrm{Lu}$ and Chipman, 1996; Freudenthaler, 2016; Ossikovski et al., 2010; David, et al., 2012). By neglecting this component, we assume that the emitting optics does not have retardation effects. This simplification can be performed once the $\alpha$ parameter is corrected and the $\beta$ angle is negligible. According to Freudenthaler (2016); David, et al. (2012), diattenuating and retarding optics such as dichroic mirrors should be carefully aligned as they can convert linear polarized light into elliptically polarized light. Another source of elliptically polarized light could be the laser emission, but according to laser specifications, the polarization purity of commercial Nd:YAG lasers is higher than $95 \%$ and the elliptical light component of the remaining light should be even lower. To overcome this issue, the residual nonpolarized laser light can be easily filtered out by including additional optics in the emission block of the lidar instrument (Engelmann et al., 2016).

The study is focused mainly on the measured calibration factor, the rotation of the plane of polarization of the laser around the propagation axis and the diattenuation parameter of the receiver optics $D_{\mathrm{O}}$ but other parameters will also be discussed further on (e.g., $D_{\mathrm{S}}$ ). The polarizing beam splitter cross talk is usually reduced by additional polarization filters placed after the PBS on both transmitted and reflected channels. Still, the cross talk effects will be included for theoretical purposes $\left(D_{\mathrm{S}}\right)$. The polarization parameter of the light beam leaving the laser $a_{\mathrm{L}}$ should be considered in the case of instruments for which the laser polarization purity is not achieved by additional optics or for which this correction is mandatory. Additional measurements are required for the assessment and correction of this parameter if this was not already provided by the laser manufacturer. Freudenthaler (2016) describes in details all terms and the variables in Eq. (1).

The light emitted by the laser is

$$
\begin{aligned}
\boldsymbol{I}_{\mathrm{L}}\left(\alpha, a_{\mathrm{L}}\right) & =\left(\begin{array}{cccc}
1 & 0 & 0 & 0 \\
0 & c_{2 \alpha} & -s_{2 \alpha} & 0 \\
0 & s_{2 \alpha} & c_{2 \alpha} & 0 \\
0 & 0 & 0 & 1
\end{array}\right) \cdot I_{\mathrm{L}}\left(\begin{array}{c}
1 \\
a_{\mathrm{L}} \\
0 \\
0
\end{array}\right) \\
& =I_{\mathrm{L}}\left(\begin{array}{c}
1 \\
c_{2 \alpha} a_{\mathrm{L}} \\
s_{2 \alpha} a_{\mathrm{L}} \\
0
\end{array}\right)
\end{aligned}
$$

where

$c_{2 \alpha}=\cos (2 \alpha)$ and $s_{2 \alpha}=\sin (2 \alpha)$.

The effects of beam expanders and steering mirrors after the laser unit can have an influence on the degree of laser polarization (David, et al., 2012). These optics can produce elliptical polarized light. For a more general approach we can define the emitter Stokes vector with an arbitrary state of polarization that could include the effects of the emitter optics $\boldsymbol{I}_{\mathrm{E}}$. To overcome the effects of the emitter optics, a good approach is to use direct laser emission without beam expansion and steering. For this case, mechanical solutions that directly align the laser with respect to the receiving unit are already available. Two of the lidar instruments considered for this study send the laser radiation into the atmosphere without using any optics (MUSA and MULIS). For lidar systems that use emitter optics to send the laser radiation into the atmosphere, further investigations are needed to fully characterize the effects of $\mathbf{M}_{\mathrm{E}}$ on depolarization products (BravoAranda et al., 2016).

$$
\begin{aligned}
\boldsymbol{I}_{\mathrm{E}}\left(\beta, \alpha, a_{\mathrm{L}}\right) & =\mathbf{M}_{\mathrm{E}}(\beta) \cdot \boldsymbol{I}_{\mathrm{L}}\left(\alpha, a_{\mathrm{L}}\right)=T_{\mathrm{E}} I_{\mathrm{L}}\left(\begin{array}{c}
i_{\mathrm{E}} \\
q_{\mathrm{E}} \\
u_{\mathrm{E}} \\
v_{\mathrm{E}}
\end{array}\right) \\
& =T_{\mathrm{E}} I_{\mathrm{L}}\left(\begin{array}{c}
1 \\
c_{2 \alpha} a_{\mathrm{L}} \\
s_{2 \alpha} a_{\mathrm{L}} \\
0
\end{array}\right)
\end{aligned}
$$

The Mueller matrix describing the atmospheric backscatter is

$\mathbf{F}(a)=\left(\begin{array}{cccc}F_{11} & 0 & 0 & 0 \\ 0 & F_{22} & 0 & 0 \\ 0 & 0 & -F_{22} & 0 \\ 0 & 0 & 0 & F_{44}\end{array}\right)$ 


$$
=F_{11}\left(\begin{array}{cccc}
1 & 0 & 0 & 0 \\
0 & a & 0 & 0 \\
0 & 0 & -a & 0 \\
0 & 0 & 0 & 1-2 a
\end{array}\right)
$$

$a=\frac{F_{22}}{F_{11}}$.

Consequently, the linear depolarization ratio of the atmospheric scattering volume $(\delta)$ can be defined as

$\delta=\frac{F_{11}-F_{22}}{F_{11}+F_{22}}=\frac{1-a}{1+a} \Rightarrow a=\frac{1-\delta}{1+\delta}$.

All optical elements $\mathbf{M}_{\mathrm{O}}$ can be described by Mueller matrices of diattenuators $\mathbf{M}_{\mathrm{D}}$ with retardation $\mathbf{M}_{\text {ret }}$ (Garcia , 2013):

$$
\begin{aligned}
\mathbf{M}_{\mathrm{O}}\left(\gamma, D_{0}\right)=\mathbf{M}_{\mathrm{D}} \mathbf{M}_{\mathrm{ret}} \mathbf{M}_{\gamma} & \\
= & T_{\mathrm{O}}\left(\begin{array}{cccc}
1 & D_{\mathrm{O}} & 0 & 0 \\
D_{\mathrm{O}} & 1 & 0 & 0 \\
0 & 0 & Z_{\mathrm{O}} & 0 \\
0 & 0 & 0 & Z_{\mathrm{O}}
\end{array}\right) \cdot\left(\begin{array}{cccc}
1 & 0 & 0 & 0 \\
0 & 1 & 0 & 0 \\
0 & 0 & c_{\mathrm{O}} & s_{\mathrm{O}} \\
0 & 0 & -s_{\mathrm{O}} & c_{\mathrm{O}}
\end{array}\right) \\
& \cdot\left(\begin{array}{cccc}
1 & 0 & 0 & 0 \\
0 & c_{2 \gamma} & -\mathrm{s}_{2 \gamma} & 0 \\
0 & s_{2 \gamma} & c_{2 \gamma} & 0 \\
0 & 0 & 0 & 1
\end{array}\right) \\
= & \left(\begin{array}{cccc}
1 & D_{\mathrm{O}} & 0 & 0 \\
D_{\mathrm{O}} & 1 & 0 & 0 \\
0 & 0 & Z_{\mathrm{O}} c_{\mathrm{O}} & Z_{\mathrm{O}} s_{\mathrm{O}} \\
0 & 0 & -Z_{\mathrm{O}} s_{\mathrm{O}} & Z_{\mathrm{O}} c_{\mathrm{O}}
\end{array}\right) \\
& \cdot\left(\begin{array}{cccc}
1 & 0 & 0 & 0 \\
0 & c_{2 \gamma} & -\mathrm{s}_{2 \gamma} & 0 \\
0 & s_{2 \gamma} & c_{2 \gamma} & 0 \\
0 & 0 & 0 & 1
\end{array}\right),
\end{aligned}
$$

with

$T_{\mathrm{O}}=\frac{T_{\mathrm{O}}^{\mathrm{p}}+T_{\mathrm{O}}^{\mathrm{s}}}{2}, D_{\mathrm{O}}=\frac{T_{\mathrm{O}}^{\mathrm{p}}-T_{\mathrm{O}}^{\mathrm{s}}}{T_{\mathrm{O}}^{\mathrm{p}}+T_{\mathrm{O}}^{\mathrm{s}}}$,

$Z_{\mathrm{O}}=\frac{2 \sqrt{T_{\mathrm{O}}^{\mathrm{p}} T_{\mathrm{O}}^{\mathrm{s}}}}{T_{\mathrm{O}}^{\mathrm{p}}+T_{\mathrm{O}}^{\mathrm{s}}}=\sqrt{1-D_{\mathrm{O}}^{2}}, c_{\mathrm{O}}=\cos \Delta_{\mathrm{O}}$,

$s_{\mathrm{O}}=\sin \Delta_{\mathrm{O}}, \Delta_{\mathrm{O}}=\varphi_{\mathrm{O}}^{\mathrm{p}}-\varphi_{\mathrm{O}}^{\mathrm{s}}$,

where $\Delta_{O}$ is the retardation (i.e., differential phase shift $(\varphi)$ of the $\mathrm{p}$ and s polarized light components), and $T^{\mathrm{p}}$ and $T^{\mathrm{s}}$ are the optics intensity transmission for parallel (p) and cross (s) linearly polarized light with respect to the plane of incidence of the PBS.

The Mueller matrix of the PBS can be defined as

$\mathbf{M}_{\mathrm{S}}\left(D_{\mathrm{S}}\right): \mathbf{M}_{\mathrm{R}}\left(D_{\mathrm{R}}\right)$ and $\mathbf{M}_{\mathrm{T}}\left(D_{\mathrm{T}}\right)$, the reflected and transmitted components as

$\mathbf{M}_{\mathrm{T}}\left(D_{\mathrm{T}}\right)=\left(\begin{array}{cccc}1 & D_{\mathrm{T}} & 0 & 0 \\ D_{\mathrm{T}} & 1 & 0 & 0 \\ 0 & 0 & Z_{\mathrm{T}} c_{\mathrm{T}} & Z_{\mathrm{T}} s_{\mathrm{T}} \\ 0 & 0 & -Z_{\mathrm{T}} s_{\mathrm{T}} & Z_{\mathrm{T}} c_{\mathrm{T}}\end{array}\right)$,

and an extra reflection matrix for the reflected component as

$\mathbf{M}_{\mathrm{R}}\left(D_{\mathrm{R}}\right)=\left(\begin{array}{cccc}1 & D_{\mathrm{R}} & 0 & 0 \\ D_{\mathrm{R}} & 1 & 0 & 0 \\ 0 & 0 & -Z_{\mathrm{R}} c_{\mathrm{R}} & -Z_{\mathrm{R}} s_{\mathrm{R}} \\ 0 & 0 & Z_{\mathrm{R}} s_{\mathrm{R}} & -Z_{\mathrm{R}} c_{\mathrm{R}}\end{array}\right)$,

By using a cleaned polarizing beam splitter (additional polarization filters placed after the PBS to minimize the amount of residual light passing in the orthogonally polarized component - the cross talk), we obtain

$$
D_{\mathrm{R}}=-1, D_{\mathrm{T}}=+1 \Rightarrow D_{\mathrm{S}}= \pm 1 .
$$

Any additional rotation of the polarization filters used for reducing the cross talk could be neglected, since these effects are well below the Rayleigh depolarization for rotation angles lower than $1^{\circ}$. The rotation matrix $\mathbf{R}(y)$ is defined as

$\mathbf{R}(y)=\left(\begin{array}{llll}1 & 0 & 0 & 0 \\ 0 & y & 0 & 0 \\ 0 & 0 & y & 0 \\ 0 & 0 & 0 & 1\end{array}\right)$,

where $y$ describes the optical setup type: $y=1$ for $90^{\circ}$ and $y=-1$ for $0^{\circ}$ (Fig. 2a-b).

With all these considerations, the detected light intensity for the $\mathrm{p}$ and c components Eq. (1) can be rewritten as follows:

$\boldsymbol{I}_{\mathrm{S}}=\eta_{\mathrm{S}} T_{\mathrm{S}} T_{\mathrm{O}} T_{\mathrm{rot}} F_{11} T_{\mathrm{E}} \boldsymbol{I}_{\mathrm{L}}\left(\mathbf{G}_{\mathrm{S}}+a \mathbf{H}_{\mathrm{S}}\right)$

with

$\mathbf{G}_{\mathrm{S}}(y, \gamma)=\left(1+y D_{\mathrm{S}} D_{\mathrm{O}} c_{2 \gamma}\right) i_{\mathrm{E}}-y D_{\mathrm{S}} Z_{\mathrm{O}} \mathrm{s}_{\mathrm{O}} \mathrm{s}_{2 \gamma} v_{\mathrm{E}}$

$$
\begin{aligned}
\mathbf{H}_{\mathrm{S}}(y, \gamma, \beta, \alpha,) \\
=D_{\mathrm{O}}\left(\mathrm{c}_{2 \gamma} q_{\mathrm{E}}-\mathrm{s}_{2 \gamma} u_{\mathrm{E}}\right)+y D_{\mathrm{S}}\left[q_{e}-s_{2 \gamma}\right. \\
\left.\quad\left[W_{\mathrm{O}}\left(s_{2 \gamma} q_{e}+c_{2 \gamma} u_{e}\right)-2 z_{\mathrm{O}} s_{\mathrm{O}} v_{e}\right]\right] .
\end{aligned}
$$

For most cases we consider $i_{\mathrm{E}}=1, q_{\mathrm{E}}=c_{2 \alpha} a_{\mathrm{L}}, u_{\mathrm{E}}=c_{2 \alpha} a_{\mathrm{L}}$, $v_{\mathrm{E}}=0$ and

$W_{\mathrm{O}}=1-Z_{\mathrm{O}} c_{\mathrm{O}}$ 


\subsection{Depolarization calibration theory}

The first parameter required for the calibration of the depolarization channels is the measured calibration factor $\eta^{*}$. This parameter includes the effects of different responsiveness for the two detection modules that are part of the depolarization channels but also crosstalk of the PBS module and optics diattenuation after the calibrator. "After" refers to the light direction given by the Mueller-Stokes formalism with respect to different optical components. Different experimental methods for assessing the measured calibration factor are presented in Sect. 3. These methods are also used to derive other instrumental depolarization parameters like the error angle of the $\Delta 90^{\circ}$ polarizer rotation calibrator $(\varepsilon), \alpha$ and the diattenuation parameter.

$\eta^{*}=\frac{\boldsymbol{I}_{\mathrm{R}}}{\boldsymbol{I}_{\mathrm{T}}}\left(\times 45^{\circ}\right)$,

where $x$ is a constant defined as \pm 1 .

For an ideal lidar instrument, the measured calibration factor should be equal to the real calibration factor $\eta$. For real lidar instruments, the measured calibration factor is affected by the latter instrumental depolarization parameters $\left(D_{\mathrm{S}}, \alpha, \varepsilon, a_{\mathrm{L}}, D_{\mathrm{O}}\right.$,). To correct for these contributions, the theoretical correction factor of the measured calibration factor must be determined $(K)$.

$\eta=\frac{1}{K} \eta^{*}$

The theoretical correction can be retrieved from the analytical expression by substitution of all known instrumental depolarization parameters. Part of the instrumental parameters can be determined by means of additional calibration measurements that will be detailed in the following sections.

$K=\frac{\eta^{*}}{\eta}=\frac{\left\langle\mathbf{A}_{\mathrm{R}}(y)\left|C\left(\times 45^{\circ}\right)\right| \boldsymbol{I}_{\text {in }}\right\rangle}{\left\langle\mathbf{A}_{\mathrm{T}}(y)\left|C\left(\times 45^{\circ}\right)\right| \boldsymbol{I}_{\text {in }}\right\rangle}$

To assess $K$, the considered lidar setups can be described using the bracket vectors. In this notation we divide the instrument optical modules into three groups: modules before the calibrator $\boldsymbol{I}_{\mathrm{in}}$, the depolarization calibrator $C\left(\times 45^{\circ}\right)$ and the modules behind the calibrator $\mathbf{A}_{\mathbf{S}}(y)$. $\mathbf{A}_{\mathbf{S}}(y)$ is the analyzer matrix and $\boldsymbol{I}_{\text {in }}$ is the input Stokes vector that includes the matrices before the calibrator and the emitted Stokes vector $\boldsymbol{I}_{\mathrm{E}}$. A detailed theoretical study on different lidar setups and positions of the depolarization calibrator can be found in Freudenthaler (2016).

The calibrated signal ratio $\delta^{*}$ can be determined by using

$\delta^{*}=\frac{1}{\eta} \cdot \frac{I_{\mathrm{R}}}{I_{\mathrm{T}}}$, and the volume linear depolarization ratio $\delta$ can be determined using

$\delta=\frac{1-a}{1+a}=\frac{\delta^{*}\left(G_{\mathrm{T}}+H_{\mathrm{T}}\right)-\left(G_{\mathrm{R}}+H_{\mathrm{R}}\right)}{\left(G_{\mathrm{R}}-H_{\mathrm{R}}\right)-\delta^{*}\left(G_{\mathrm{T}}-H_{\mathrm{T}}\right)}$.

\section{Methodology}

\subsection{Assessment of the measured calibration factor $\eta^{*}$ : calibration procedures}

The calibration of depolarization channels is specific to each lidar system but the basic principles are similar for most of the instruments. The calibration of the depolarization channels consists of assessing the measured calibration factor $\eta^{*}$ and then applying all necessary corrections to reduce the contribution of the instrument.

In order to determine the measured calibration factor $\eta^{*}$, a first approach is to use the $0^{\circ}$ calibration or the atmospheric calibration. Using this calibration, the contribution of the system to the final lidar depolarization products is assessed by using a low aerosol height range in the lidar signal at an altitude at which only the molecular contribution is assumed. In this atmospheric region, the total volume linear depolarization ratio can be approximated by the wellknown value of the air molecular linear depolarization ratio (Behrendt and Nakamura, 2002). Usually this procedure can introduce additional uncertainties, since for an accurate calibration at least two reference points are required. Another drawback is the presence of small amounts of highly depolarizing aerosol (e.g., ice crystals) in the assumed clean range that can easily lead to large errors in the depolarization products (Freudenthaler et al., 2009; Freudenthaler, 2016). Other calibration techniques include the use of depolarization optics in the receiver to calibrate the lidar gain ratio (Winker et al., 2007) or the use of three lidar signals (cross, parallel and total) to calibrate the depolarization products. The three lidar signals method makes use of two altitude ranges - highdepolarization and low-depolarization load - to extract the calibration constant for the calibration channels (Reichardt et al., 2003).

A reliable solution for calibrating the depolarization measurements is represented by the $45^{\circ}$ calibration. This calibration implements a $45^{\circ}$ rotation of the depolarization analyzer (PBS and the PMTs) with respect to the polarization plane of the laser in order to equalize the light intensity in the cross and parallel channels. When comparing the calibration signals, the ratio between the transmitted and reflected signals reflects the contribution of optics and electronics in the lidarreceiving unit. The implementation of these methods will be further described in this study.

The main source of uncertainty involved in this kind of calibration is represented by the accuracy which determines the $45^{\circ}$ rotation with respect to the true zero position of the PBS: 
the lower this accuracy, the larger the errors in estimating the calibration constant. A better solution is to use two subsequent measurements taken by rotating the depolarization analyzer at $\pm 45^{\circ}$ with respect to the default measuring position (David, et al., 2012). This calibration is called the " $\pm 45^{\circ}$ calibration". The calibration constant is determined by using the geometric mean of the two $\pm 45^{\circ}$ measurements. The two measurements are designed to compensate each other even for cases in which the $45^{\circ}$ rotation uncertainty is large with respect to the initial zero position given by the PBS (Freudenthaler et al., 2009). Since for the $\pm 45^{\circ}$ calibration, the initial zero position reference is not important, a more general solution is to use two subsequent measurements taken by rotating the depolarization analyzer with an exact $90^{\circ}$ difference between them. This calibration method is called the " $\Delta 90^{\circ}$ calibration" and the output is similar to the one from the $\pm 45^{\circ}$ calibration. The $\pm 45^{\circ}$ calibration can be considered a particular case of the $\Delta 90^{\circ}$ rotation calibration, since the only constraint of this calibration is the $90^{\circ}$ angle between the two measurements.

Technically, the $\Delta 90^{\circ}$ calibration can be implemented by using a mechanical rotator (holder) that rotates the optical components at fixed $\Delta 90^{\circ}$ angles. This calibrator will be called the " $\Delta 90^{\circ}$ mechanical rotation calibrator". A similar approach (same output) can be considered if we use a half-wave plate (HWP) to accurately rotate the emitted or collected light at $\Delta 90^{\circ}$. The advantage is that, while the mechanical rotator can only be placed in the reception unit (in front of the receiving optics or in front of the PBS), the HWP module can be also placed at the emission, in front of and after the emission optics. This calibrator will be called the " $\Delta 90^{\circ} \mathrm{HWP}$ calibrator". A third approach of the $\Delta 90^{\circ}$ calibration is the use of an additional linear polarizer that can be rotated at fixed $\Delta 90^{\circ}$ angles. In this case, the $\Delta 90^{\circ}$ rotation will be replaced with the additional linear polarizer. According to its position in the optical chain (in front of the telescope, receiving optics or the PBS) the calibration can account for all lidar optics placed after the polarizer (e.g., receiving optics, PBS, PMT). This is also valid for the other calibrators. Further on, this calibrator will be called the " $\Delta 90^{\circ}$ polarizer rotation calibrator". Table 1 summarizes main advantages and disadvantages when using different calibration techniques for the $\Delta 90^{\circ}$ calibration. In order to perform the latter calibration, the "zero" position of the optical module with respect to the relative position of the PBS must be determined and corrected for. To do this, the $\Delta 90^{\circ}$ rotation calibration requires setting an extra measurement to assess the error angle caused by the offset between the calibrator and the zero position of the PBS. The error angle of the calibration setup $(\varepsilon)$ must be estimated to allow a reliable measurement of the calibration constant when using the $\Delta 90^{\circ}$ polarizer calibration. The calibration error angle $\varepsilon$ has to be corrected either mechanically before the measurements or analytically after the measurements. To determine $\varepsilon$, a set of two relative $\Delta 90^{\circ}$ measurements is required. The polar- izer is placed in a random position relative to the polarization plane of the receiving optics. Two measurements will be performed with the polarizer rotated precisely at $\pm 45^{\circ}$ from the $\varepsilon$ angle to derive $\eta^{*}\left(y,+45^{\circ}, \varepsilon, K\right)$ and $\eta^{*}\left(y,-45^{\circ}, \varepsilon, K\right)$.

Freudenthaler (2016) shows that the $\varepsilon$ angle can be determined defining $Y$ as follows:

$Y(\varepsilon, K)=\frac{\eta^{*}\left(y,+45^{\circ}, \varepsilon, K\right)-\eta^{*}\left(y,-45^{\circ}, \varepsilon, K\right)}{\eta^{*}\left(y,+45^{\circ}, \varepsilon, K\right)+\eta^{*}\left(y,-45^{\circ}, \varepsilon, K\right)}$,

and

$\varepsilon=\frac{1}{2} \arcsin \left[\frac{1}{K} \tan \left(\frac{\arcsin (Y(\varepsilon, K))}{2}\right)\right]$.

Note that the assessment of the calibrator rotation angle can only be performed under stable atmospheric conditions.

Another method to correct for the $\varepsilon$ angle is by looking at relatively clean and stable atmosphere regions and minimizing the cross polarized signal. In addition, one would look at minimizing the difference in complementary angles $( \pm)$ from the assumed angle and iterating (this assumes that there is no ellipticity in the laser beam or retardation effect in the receiver).

The particularity of the $\Delta 90^{\circ}$ calibration also enables the assessment of other instrumental depolarization parameters required for the theoretical correction of the calibration factor - Eq. (21). Equations (24) and (25) show how the $\Delta 90^{\circ}$ calibration is used to quantify the $(\varepsilon)$ angle of the $\Delta 90^{\circ}$ polarizer rotation calibrator. Sect. 3.3 shows how the $\Delta 90^{\circ}$ calibration is used to quantify the diattenuation parameter for individual optical modules. Section 3.4 shows how this calibration is used to quantify the rotation of the plane of polarization of the laser around the propagation axis $(\alpha)$.

This study will present the implementation of all these calibration methods, according to specific lidar setups in the EARLINET network but also the methods with which to assess different instrumental depolarization parameters required to correct the measured calibration factor. A comparison between these different calibration methods, advantages and disadvantages and possible error sources is also discussed and analyzed.

\subsection{Assessment of the measured calibration factor $\eta^{*}$ : experimental solutions}

\subsection{1 $\Delta 90^{\circ}$ mechanical rotation calibrator and HWP calibrator}

The first experimental setup for the lidar depolarization calibration is based on the calibrator module placed in front of the polarizing beam splitter $(\mathrm{Cl}$ in Fig. 3a) or in front of the receiving optics $\left(\mathrm{C} 2\right.$ or $\mathrm{C}^{\prime}$ in Fig. 3a). The calibrator consists of a high-precision mechanical rotator implementing rigid rotations of the PBS and PMTs at $+45^{\circ}$ and $-45^{\circ}$ with respect to the default measuring angle (considered the 
Table 1. $\Delta 90^{\circ}$ calibration methods. "+" shows advantage and "-" shows disadvantage over other presented methods.

\begin{tabular}{lllll}
\hline Type & SNR & Effect on measurements & Position & Automated \\
\hline$\Delta 90^{\circ}$ mechanical rotation calibrator & + & not removed after calibration & in receiving unit & + \\
$\Delta 90^{\circ}$ HWP calibrator & + & removed after calibration & also in emitter unit & + \\
$\Delta 90^{\circ}$ polarizer rotator calibrator & - & removed after calibration & in receiving unit & + \\
\hline
\end{tabular}

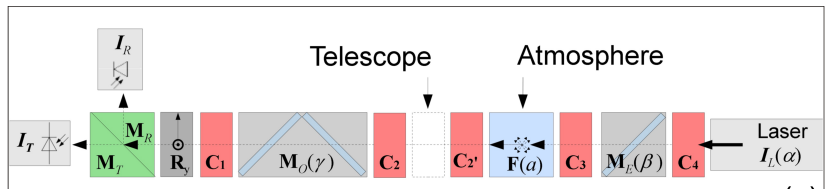

(a)

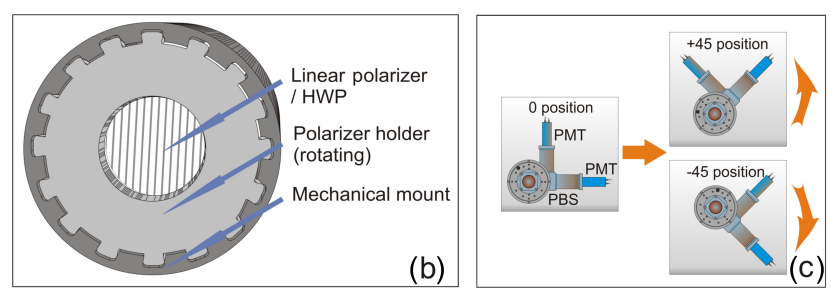

Figure 3. Calibration blocks: (a) schematics of a polarization sensitive lidar system with Mueller matrix block elements, different calibrator positions (red blocks - C); (b) multi-angle mechanical rotator mount for the $\Delta 90^{\circ}$ polarizer calibrator or the $\Delta 90^{\circ}$ optical calibrator. $22.5^{\circ}$ rotation step. HWP is a half-wave plate; (c) mechanical rotator for the $\Delta 90^{\circ}$ mechanical calibrator. PMT is a photomultiplier, PBS is a polarizing beam splitter.

$0^{\circ}$ position) (Fig. 3c). By rotating the calibration module at $+45^{\circ}$ or $-45^{\circ}$, the light intensities in the transmitted and reflected paths are equalized independent of the atmospheric depolarization.

The $\Delta 90^{\circ}$ calibration provides the measured calibration factor $\eta^{*}\left( \pm 45^{\circ}\right)$.

The Athens EARLINET station (Kokkalis et al., 2013) operates depolarization lidars using a mechanical rotator in front of the PBS for the $\Delta 90^{\circ}$ calibration (Mamouri et al., 2012).

Another approach with similar results to the $\Delta 90^{\circ}$ mechanical rotation calibrator is the use of a HWP to rotate the plane of polarization of the collected light to the desired angles (in this case $\pm 45^{\circ}$ ). This calibrator is called the " $\Delta 90^{\circ}$ HWP calibrator". The HWP rotator calibrator has the same effect and uses the same formulas as the mechanical rotator calibrator. In addition to the mechanical rotation calibrator, the HWP calibrator can also be placed in the emission block of the lidar system (C3 and C4 in Fig. 3a).

This calibration method is used, for example, by the Munich (MULIS) (Freudenthaler et al., 2009) and Potenza (MUSA) lidar systems (Madonna et al., 2011). In both these systems the calibration module consists of a HWP rotator placed in front of the PBS, which rotates the plane of polar- ization of the light by $\pm 45^{\circ}$ with respect to the default polarization angle. The same type of calibrator can be also implemented by using a stepping motor rotation mount or a HWP mount which is placed in a holder with fixed and accurate positions at $0^{\circ}$ and $\pm 45^{\circ}$ (or multiple positions) (Fig. 3b). Dual-wavelength polarization lidars need a HWP for each wavelength to perform the calibration (a HWP for 532 would be a quarter wave plate for 1064 and introduce circular or elliptical polarization).

An advantage when using this method is that measurements are not affected by the calibrator itself. The $\Delta 90^{\circ}$ mechanical rotation calibration introduces an angle error $(\Psi)$ that is always present in the measurement, whereas for cases in which the $\Delta 90^{\circ} \mathrm{HWP}$ calibrator is removed after the calibration procedure, any errors introduced by the multi-angle polarizer calibrator or the HWP calibrator will not have any effect on the measurements.

\subsection{2 $\Delta \mathbf{\Delta 9 0}^{\circ}$ polarizer rotator calibrator}

The third approach for the lidar depolarization calibration at $\Delta 90^{\circ}$ is the use of a linear polarizer. This type of calibrator can be implemented by using the mechanical rotating ring or the stepping motor rotation mount used for the HWP calibrator (Fig. 3b). The calibrator can be placed in front of the polarizing splitter $\left(C_{1}\right.$ in Fig. $\left.3 \mathrm{a}\right)$, in front of the receiving optics $\left(C_{2}\right.$ or $C_{2}^{\prime}{ }_{2}$ in Fig. 3a). Several EARLINET lidar systems are using this calibration technique in different versions. The cost efficiency and simple design of this calibrator makes it easy to implement and also easy to use. Moreover, as it is quite a compact optical element, typically, it does not take up much space in the majority of the lidar optical chains.

Leipzig and Evora lidar stations operate POLLY-XT multiwavelength depolarization Raman lidar systems (Althausen, 2013) with cross and total depolarization channels at 532 and $355 \mathrm{~nm}$ (Leipzig) and $532 \mathrm{~nm}$ (Evora) (Fig. 2c). Calibration of the depolarization channels for these instruments is performed using the $\pm 45^{\circ}$ rotable polarizer, placed in front of the detection optics or near the telescope's field stop. For this case, the acceptance angles of the polarizer used for calibration must be accounted for, since the calibration requires high extinction ratios.

All experimental setups presented in this section are based on the " $\Delta 90^{\circ}$ calibration" procedure; therefore the methodology describing the assessment of the lidar depolarization calibration constant is similar for all calibrators described in 
the study. For all these calibration procedures, the measured calibration factor can be derived from the geometric mean of the two consecutive measurements at $-45^{\circ}$ and $+45^{\circ}$.

For a general approach, the theoretical framework describing the assessment of the measured calibration factor for the lidar depolarization channels is described in detail by Freudenthaler (2016).

\subsection{Assessment of the diattenuation parameter $D_{0}$}

This section provides information on how the $\Delta 90^{\circ}$ calibration can be used to assess the diattenuation parameter of the receiving optics. This measurement is important for lidar instruments that use depolarization calibration techniques in front of the PBS. For this case, one additional measurement is required to assess the contribution of the receiving optics $\left(D_{\mathrm{O}}\right)$ to the depolarization products each time changes are performed to the receiving optics or the laser. The parameter will be later used to correct the measured calibration factor and to assess the $H_{\mathrm{S}}$ and $G_{\mathrm{S}}$ parameters.

By comparing the calibration values obtained using the two calibrators placed in front of and after a specific optical module, the investigator can assess its depolarization effects (quantify the $D_{\mathrm{O}}$ value). Simulations performed by (BravoAranda et al., 2016) shows that the effect of $D_{\mathrm{O}}$ on depolarization products are highly significant. By using this method, we can correct its effect for either the receiving optics (if the calibration modules are placed in front and after the receiving optics), the emitting optics (if the calibration modules are placed in front of the emitting optics and in front of the receiving optics) or both. Once $D_{\mathrm{O}}$ is known, we can correct for its effect regardless of the calibrator's default position in the optical chain.

Several systems, such as lidars operated by Munich (MAISACH) (Freudenthaler et al., 2009), Granada (MULHACEN) (Guzman et al., 2013; Bravo-Aranda et al., 2016) or Bucharest stations (RALI) (Nemuc et al., 2013), have two or more depolarization calibration methods implemented. Both Granada and Bucharest stations run multiwavelength Raman depolarization lidars, measuring on two depolarization channels at $532 \mathrm{~nm}$ and a $90^{\circ}$ setup (Fig. 2a). The depolarization calibration setup consists of a set of two calibration modules/techniques, designed to evaluate the contribution of certain lidar sections on the output depolarization products $\left(D_{\mathrm{O}}\right)$.

The first calibrator is a mechanical rotator (with a rotation accuracy better than $\pm 0.1^{\circ}$ ) placed in front of the PBS $-C_{1}$ in Fig. 3a (for the $\Delta 90^{\circ}$ calibration), which provides the calibration value named $\eta_{\text {after }}^{*}$.

The second calibrator consists of a linear polarizer mounted in front of the telescope's field stop or in front of the receiving block $\left(\mathbf{M}_{\mathrm{O}}\right)$ of the lidar system $\left(C_{2}\right.$ and $C_{2}^{\prime}$ in Fig. 3a), providing the calibration value named $\eta_{\text {before }}^{*}$ A mechanical mount allows the polarizer to rotate by a fixed $22.5 \pm 0.05^{\circ}$ rotating steps (Fig. 3b). By comparing the re-
Table 2. Calibration values for EARLINET lidar systems performing depolarization calibration measurements.

\begin{tabular}{lrrrrrr}
\hline Site & $\eta_{\text {after }}$ & $\Delta \eta_{\text {after }}$ & $\eta_{\text {before }}$ & $\Delta \eta_{\text {before }}$ & $D_{O}$ & $\Delta D_{O}$ \\
\hline Granada & 0.14 & \pm 0.03 & 0.24 & \pm 0.03 & 0.35 & \pm 0.04 \\
Bucharest & 1.15 & \pm 0.08 & 1.9 & \pm 0.1 & 0.227 & \pm 0.1 \\
Potenza & 22.67 & \pm 0.10 & 25.3 & \pm 0.10 & -0.055 & \pm 0.01 \\
Athens & 0.054 & \pm 0.01 & - & - & - & - \\
Leipzig & - & - & 0.089 & \pm 0.01 & - & - \\
Munich & 42.2 & \pm 0.4 & 47.5 & \pm 0.9 & 0.059 & \pm 0.015
\end{tabular}

sults obtained using the two calibrators, the diattenuation of the optical elements in between $\left(\mathbf{M}_{\mathrm{O}}\right)$ can be determined.

For lidar systems like the ones from Potenza and Munich, the diattenuation effect of the receiving optics $\left(\mathbf{M}_{\mathrm{O}}\right)$ is known to be low due to a particular design of the optical module (optimized angles) and special manufactured optical components designed to reduce the diattenuation effects. In the case of Bucharest and Granada lidar systems, the influence of the receiving optics is known to have a greater impact on the depolarization products - see Table 2 . The diattenuation effects can be corrected in the post-measurement analysis if the $D_{\mathrm{O}}$ parameter of the considered optical module is determined.

The diattenuation of the receiving optics can be easily determined by assessing the following ratio:

$\eta^{*}\left(D_{\mathrm{O}}\right)=\frac{\eta_{\text {before }}^{*}\left( \pm 45^{\circ}\right)}{\eta_{\mathrm{after}}^{*}\left( \pm 45^{\circ}\right)}=\frac{1+D_{\mathrm{O}}}{1-D_{\mathrm{O}}}$,

leading to

$D_{\mathrm{O}}=\frac{\eta_{\text {before }}^{*}\left( \pm 45^{\circ}\right) / \eta_{\mathrm{after}}^{*}\left( \pm 45^{\circ}\right)-1}{\eta_{\text {before }}^{*}\left( \pm 45^{\circ}\right) / \eta_{\mathrm{after}}^{*}\left( \pm 45^{\circ}\right)+1}$.

\subsection{Assessment of and correction for the laser rotation $\alpha$}

Orientation of the plane of polarization of the laser around the propagation axis is not accurately provided by laser manufacturers. The mechanical assembly between the laser and the receiver optics can often contribute to the rotation between the laser emission and the PBS, since the accuracy of these assemblies is lower that the alignment accuracy of the optical elements. The alignment mechanism of the lidar instrument used to tilt the laser beam could also be a source of variability and uncertainty. Considering these limitations, it is important to assess the laser rotation around the propagation axes $(\alpha)$. For large values, the effects of this parameter are significant and must be accounted for.

To assess the effects of $\alpha$ on the depolarization ratio and to determine the best experimental solution to correct for this parameter, several simulations were performed for the Bucharest lidar system. The main goal of these simulations is to stress the effects on the rotated input Stokes vector transmitted on different optics and to show the reader how differ- 

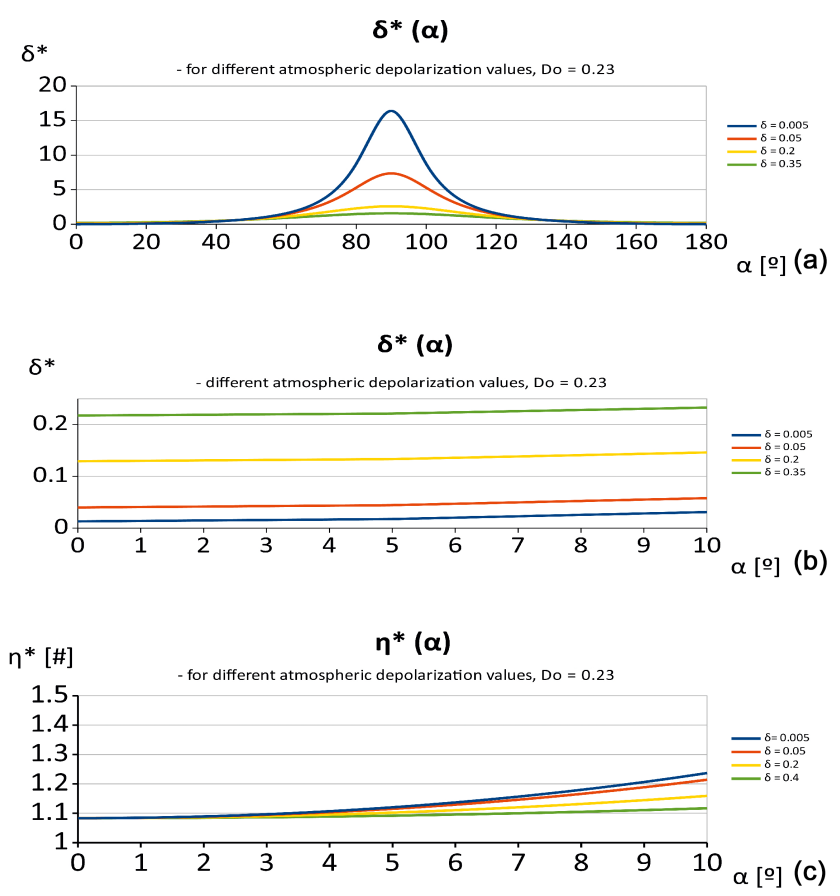

Figure 4. Numerical simulation: (a) calibrated signal ratio vs. $\alpha$ simulations for different atmospheric depolarization values $\alpha\left(0^{\circ}: 180^{\circ}\right)$; (b) calibrated signal ratio vs. $\alpha$ simulations for different atmospheric depolarization values $-\alpha\left(0^{\circ}: 10^{\circ}\right)$; (c) $\eta-\alpha$ simulations for different atmospheric depolarization values.

ent correction methods are affecting the volume linear depolarization ratio. Figure $4 \mathrm{a}-\mathrm{b}$ shows simulations of calibrated signal ratio as a function of $\alpha$. The simulations demonstrate that, for angles smaller than $3^{\circ}$, the effect on the calibrated signal ratio is negligible (Fig. 4b). The effects induced on the calibrated signal ratio increase dramatically for higher values of the angles (Fig. 4a). According to these simulations, the effects of $\alpha$ are also dependent on atmospheric depolarization: as atmospheric depolarization decreases, the dependence between the calibrated signal ratio and $\alpha$ is more significant. In real situations, the optical misalignment for $\alpha$ will not exceed $10-15^{\circ}$, but in order to present a complete dependency of the calibrated signal ratio, Fig. 4a shows the behavior of the latter for $\alpha$ ranging from 0 to $180^{\circ}$.

Simulations of measured calibration factor $\left(\eta^{*}\right)$ obtained using the mechanical rotation in front of the PBS (Fig. 4c) show the dependency of the latter with atmospheric depolarization for $\alpha$ ranging from 0 to $10^{\circ}$. This dependency alters the experimental retrieval of the measured calibration factor whenever $\alpha$ is considerable large $\left(\alpha>5^{\circ}\right)$. Good practice would be to assess and correct for the $\alpha$ angle before performing the depolarization calibration. Since the correction of $\alpha$ can be realized either by experimental techniques or by post-processing analytical corrections, the latter statement only applies to the experimental solutions.

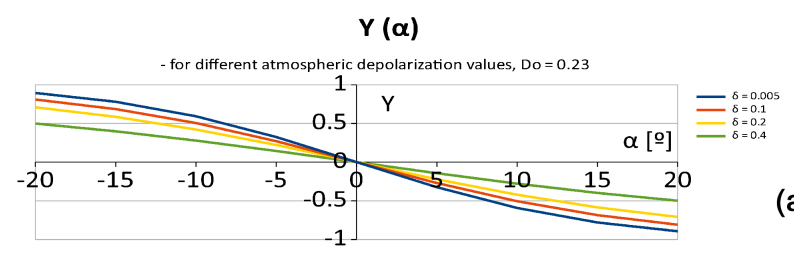

(a)
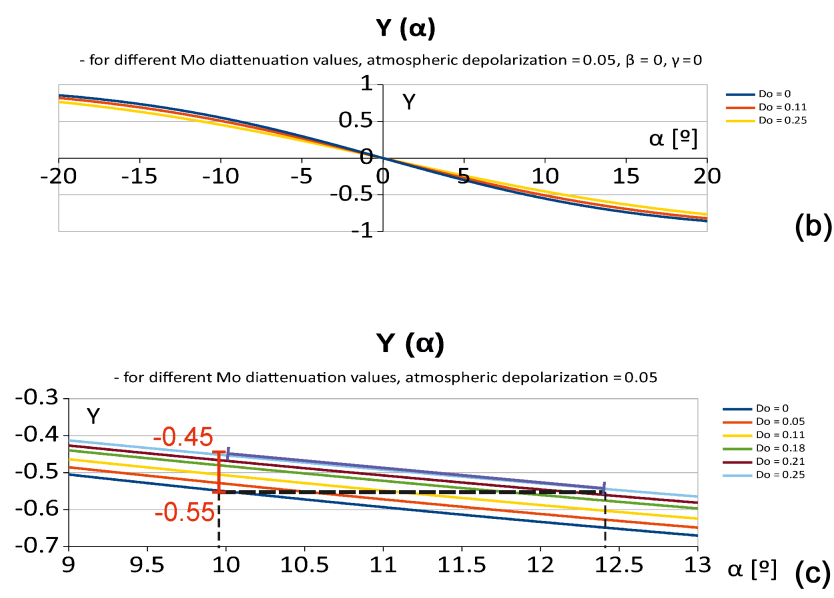

Figure 5. Numerical simulation: (a) $Y-\alpha$ simulations for several atmospheric depolarization values; (b) $Y-\alpha$ simulations for several diattenuation values; (c) $Y-\alpha$ simulations for several diattenuation values - zoomed in.

\subsubsection{Assessment of $\alpha$ parameter}

In order to determine $\alpha$, we apply the same principles as for assessing the calibrator rotation angle $-\varepsilon$ for the $\Delta 90^{\circ}$ polarizer rotator calibrator (Alvarez et al., 2006; David, et al., 2012; Freudenthaler, 2016).

Simulations in Fig. 5a-b show a strong dependency between $Y$ (which was introduced in Eq. (24) and is mathematically related to the error angle) and two other parameters: the depolarization parameter of the atmospheric volume and the diattenuation parameter of the receiving optics. The dependency of $Y$ with the polarization parameter of the atmosphere does not affect the assessment of $\alpha$ drastically, since all the retrievals are performed in an aerosol-free height, where the atmospheric depolarization is minimal. Although simulations reveal a notable link between $Y$ and the latter parameters, this dependency becomes negligible as the $\alpha$ value decreases. This particularity allows a highly accurate experimental correction of $\alpha$ by applying an iterative procedure: after the first iteration (first $\alpha$ assessment and experimental correction), the effects of the atmospheric depolarization parameter and the diattenuation on the second $\alpha$ assessment are decreased and the correction becomes more and more accurate. The second iteration is performed for smaller $\alpha$ values therefore it has a better accuracy. After several iterations, the retrieved $\alpha$ value will be close to zero. The iteration method does not apply to the analytical correction of $\alpha$. 


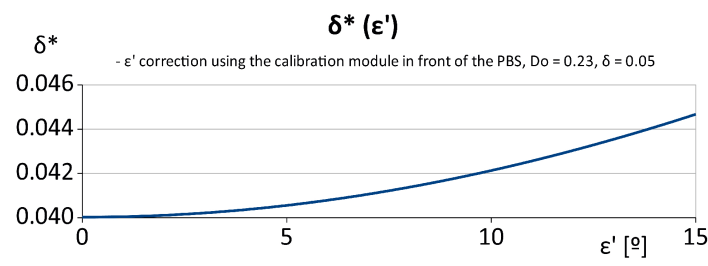

(a)

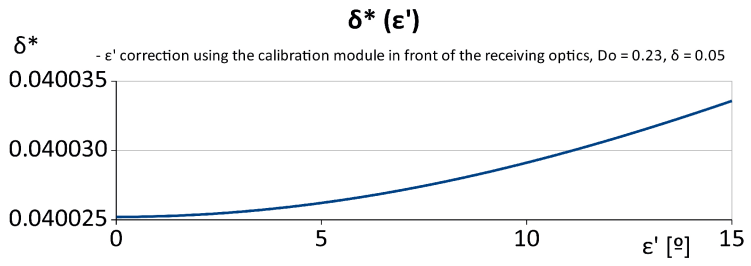

(b)

Figure 6. Numerical simulation: (a) calibrated signal ratio vs. $\varepsilon^{\prime}$ when using the $\alpha$ correction module in front of the PBS (b) measured depolarization ratio vs. $\varepsilon^{\prime}$ when using the $\alpha$ correction module in front of the receiving optics.

\subsubsection{Correction for the $\alpha$ parameter}

The analytical correction of $\alpha$ can be performed by determining $G_{\mathrm{S}}, H_{\mathrm{S}}$ and $K$ using Eqs. (16), (17) and (21). According to simulations (Fig. 5c), uncertainties associated with the assessment of $\alpha$ (for the analytical correction) can go up to $25 \%$ for a $10^{\circ}$ initial offset and a diattenuation value $D_{\mathrm{O}}$ ranging from 0 to 0.25 . The experimental correction of $\alpha(Y)$ can be performed either by rotating the PBS in the WSU (without or together with the receiving optics) or by rotating the plane of polarization of the collected light using a HWP placed in front of the PBS or in front of the receiving optics (in the case of one wavelength lidar instruments or systems with separate optics for the depolarization channels, since a HWP used to correct for alpha works only if the depolarization measurement is performed at a single wavelength). In the case of the total-cross-detection setup (Fig. 2c), the experimental correction of $\alpha(Y)$ could also be accomplished by rotating the linear polarizer placed in front of the detection module.

\section{In front of the PBS}

For lidar systems designed to use the mechanical rotation calibrator in front of the PBS, the most efficient technique with which to correct for $\alpha$ is by rotating the PBS according to its determined value. Equivalent results can also be obtained by rotating the laser polarization plane by means of a HWP module placed in front of the PBS. For the $\alpha$ correction, the compensation angle of the correction module will be considered $\varepsilon^{\prime}$.

Simulations of the calibrated signal ratio corrected with $\varepsilon^{\prime}$ are presented in Fig. 6a (for $\alpha=-\varepsilon^{\prime}$ ). The results show that for $\varepsilon^{\prime}=10^{\circ}$, the correction error reaches $3 \%$ from the absolute value of the calibrated signal ratio. This error is most probably caused by the method itself: when using the mechanical rotation or HWP rotation in front of the PBS, we compensate for $\alpha$ after the light has gone through the receiving optics $\left(\mathbf{M}_{\mathrm{O}}\right)$. The effects introduced by $\alpha$ in the receiving optics as the collected backscattered light is guided toward the PBS are not removed by this correction. We must stress that, in order to perform a comprehensive simulation, the diattenuation parameter of the receiving optics was considered 0.23 (measured diattenuation for the Bucharest RALI lidar system - Table 2) and the atmospheric depolarization 0.05 (since higher values for the atmospheric depolarization will not drastically alter the correction error).

\section{In front of the receiving optics}

For lidar systems designed to use a mechanical rotation calibrator in front of the receiving optics, the optimal technique designed to correct for $\alpha$ is by rotating the receiving optics accordingly. This technique is considered to be better, since by rotating both the receiving optics and the PBS, all the effects introduced by $\alpha$ in the receiving optics are compensated for.

For the case of one wavelength emission, a HWP calibrator placed in front of the receiving optics can also be used to correct for $\alpha$. In the case of lidar instruments having different emission axes at different wavelengths, the correction could be performed at the emission.

For this case, the simulations show that the linear depolarization ratio error is less than $0.1 \%$ for a $10^{\circ}$ offset (Fig. 6b).

\section{Results and discussions}

Numerous optical components inside the lidar's emission and receiving units can lead to large systematic errors of the atmospheric depolarization values (Bravo-Aranda et al., 2016). Methods designed to assess and correct instrumental effects on the depolarization channels are constantly under development. The volume linear depolarization ratio profiles show significant improvements when reliable and accurate depolarization calibration techniques are used. The impact of the calibration is mostly visible in the low aerosol height ranges, where the rather low molecular contribution is usually added to the systematic error of the instruments. The particle linear depolarization ratio profiles are also improved by the calibration, although in this case, the uncertainties also include the contribution of the aerosol backscatter coefficient (Freudenthaler et al., 2009).

\subsection{The measured calibration factor $\eta^{*}$}

The measured calibration factor and diattenuation values for several calibration methods are presented in Table 2. $\eta_{\text {before }}^{*}$ represents the measured calibration factor value retrieved using the $\Delta 90^{\circ}$ polarizer rotator calibrator placed in front of the receiving optics and $\eta_{\text {after }}^{*}$ represents the measured cal- 

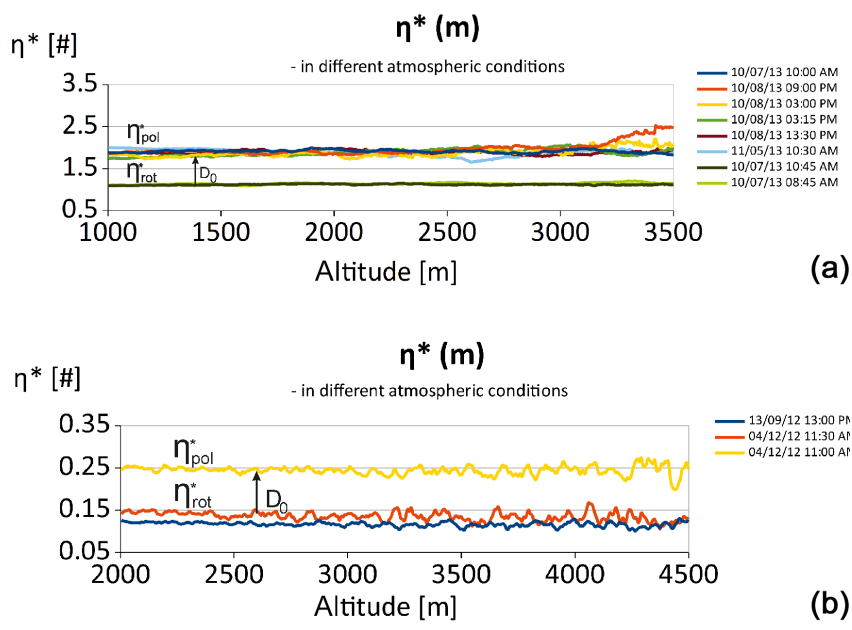

Altitude [m]

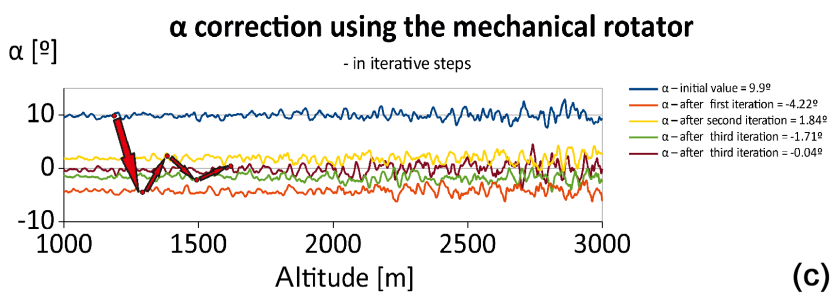

Figure 7. Calibration values using two experimental techniques: polarizer rotation calibrator $\left(\eta_{\text {before }}^{*}\right)$ and mechanical rotation calibrator $\left(\eta_{\mathrm{after}}^{*}\right)$ (a) for the Bucharest lidar; (b) for the Granada lidar. (c) Assessment and correction of $\alpha(Y)$ parameter for the Bucharest lidar using the iterative procedure, mechanical rotator in front of the PBS.

ibration factor value retrieved using either the $\Delta 90^{\circ} \mathrm{HWP}$ calibrator or the $\Delta 90^{\circ}$ mechanical rotation calibrator, placed in front of the PBS. Deviation values are retrieved either from consecutive measurements collected during a limited time interval or from the variability of the measured calibration factor in the selected altitude interval.

\subsection{The diattenuation parameter $D_{0}$}

The diattenuation parameters for the Potenza and Munich systems show values that are 1 order of magnitude lower than for the rest of the lidar systems (Table 2).

Figure $7 \mathrm{a}-\mathrm{b}$ show the measured calibration factor retrieved using two experimental techniques for the Granada and Bucharest systems in order to extract the diattenuation value as presented in Sect. 3.3. The difference between the $\eta_{\text {before }}^{*}$ and $\eta_{\text {after }}^{*}$ represents the effect of the receiving optics diattenuation parameter $\left(D_{\mathrm{O}}\right)$ on the depolarization value.

Figure 7a-b illustrates the height dependence of the measured calibration factor retrieved by using two depolarization calibration modules. The results show that, for the presented altitudes, the height dependence of the calibration value is not significant (for neither the Bucharest nor Granada lidar systems). For the Bucharest system, the measured calibra- tion factor profiles from 1 to $3.5 \mathrm{~km}$ show higher stability for the mechanical rotator retrievals $\left(\eta_{\mathrm{after}}^{*}\right)$ with respect to the polarizer rotation retrievals $\left(\eta_{\text {before }}^{*}\right.$ ). This stability difference could be caused by the presence of atmospheric layers with higher depolarization signature in the investigated range, changing rapidly with time. For the Granada system, the profiles show the same stability for both $\eta_{\text {before }}^{*}$ and $\eta_{\text {after }}^{*}$. The height dependence for the measured calibration factor could be used as a good indicator of potential problems in the optical layout of the lidar system.

\subsection{Rotation of the plane of polarization of the laser $(\alpha)$}

One parameter that has a significant impact on depolarization products is the rotation of the plane of polarization of the laser with respect to the PBS: $\alpha$. According to numerical simulations already presented, correction of the $\alpha$ parameter can be achieved by using a mechanical rotator or a HWP placed in front of the PBS or in front of the receiving optics. A third option is the post-measurement analytical correction performed once the $\alpha$ parameter is retrieved. Further on in the following section, in order to perform comparisons between corrected and noncorrected lidar profiles, the first case study will only consider the post-measurement analytical correction for $\alpha$.

Figure $7 \mathrm{c}$ shows results of the assessment and correction of the $\alpha$ parameter for the Bucharest system using the mechanical rotator in front of the PBS. The correction is performed by iterative steps by means of rotating the linear analyzer (PBS) in accordance with measured $\alpha$ values. The values show that measured $\alpha$ reaches a value equal to $-0.04^{\circ}$ after four iterations. The impact of the $\alpha$ correction on the depolarization profiles can be easily emphasized for the postmeasurement analytical correction presented in Sect. 3.4.2. Figure $8 \mathrm{a}-\mathrm{c}$ shows an example of volume and particle linear depolarization ratios from 26 September 2013, measured by the Bucharest lidar system RALI (Nemuc et al., 2013).

The range-corrected time series for $532 \mathrm{~nm}$ total (parallel + cross) show stable layers in the lower troposphere and ice clouds above $8 \mathrm{~km}$ (Fig. 8a, red vertical lines) show the averaged time period considered for the calculation of the volume linear depolarization profiles. The noncalibrated volume linear depolarization profiles (the ratio of the two signals) show values reaching up to 0.27 in the ice cloud and 0.12 in the free troposphere (Fig. 8b). The calibrated profile $\left(\eta^{*}, a_{\mathrm{L}}, D_{\mathrm{O}}\right.$ corrected, no $\alpha$ correction) shows lower values in the free troposphere and values reaching 0.42 in the ice cloud (see Table 3 ). For this case study, the polarization parameter of the laser was determined to $0.970 \pm 0.005$. After correction of $\alpha$, the volume linear depolarization values reaches out to 0.40 in the cloud and close to the molecular in the free troposphere (Sassen et al., 2007; Sassen, 2005) (for this case $\alpha=10^{\circ}$ ). Table 3 shows noncalibrated and calibrated (including $\alpha$ correction) volume linear depolarization retrievals in two cases: in the cloud layer and in the free tro- 

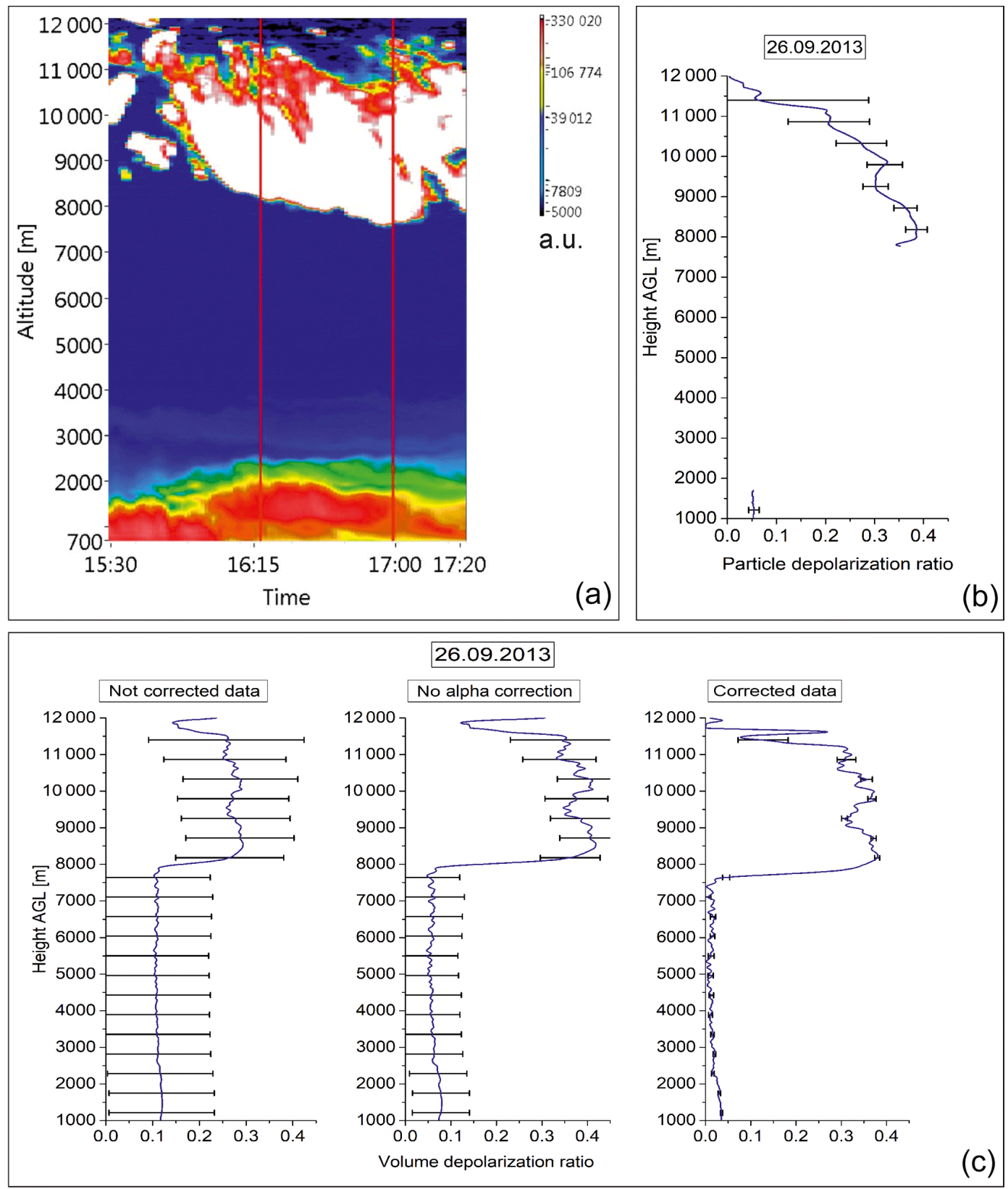

Figure 8. Data from 26 September 2013 at the RALI-Bucharest lidar system. (a) Range-corrected time series at $532 \mathrm{~nm}$; (b) volume linear depolarization ratios for noncorrected, $\left(\eta^{*}, a_{\mathrm{L}}, D_{\mathrm{O}}\right)$ corrected and $\left(\eta^{*}, a_{\mathrm{L}}, D_{\mathrm{O}}\right)$ and $\alpha(Y)$ corrected profile at $532 \mathrm{~nm}$ with smoothed data, $45 \mathrm{~min}$ time average and $45 \mathrm{~m}$ vertical smoothing; (c) particle depolarization ratio profile at $532 \mathrm{~nm}$ with smoothed data, 45 min time average and $45 \mathrm{~m}$ vertical smoothing.

Table 3. Volume linear depolarization values of calibrated and non-calibrated retrievals for the RALI lidar system on 26 September 2013.

\begin{tabular}{lrrrr}
\hline & $\begin{array}{r}\text { Non-calibrated } \\
\text { profiles }\end{array}$ & $\begin{array}{r}\eta^{*}, a_{L}, D_{O} \\
\text { corrected, } \\
\text { no } \alpha \text { correction }\end{array}$ & $\begin{array}{r}\eta^{*}, a_{L}, D_{O} \\
\text { corrected, } \\
\alpha \text { correction }\end{array}$ & $\begin{array}{r}\text { Difference between non- } \\
\text { calibrated and } \\
\text { calibrated profiles } \\
(\alpha \text { corrected })\end{array}$ \\
\hline Cloud $(8.5-10.5 \mathrm{~km})$ & 0.27 & 0.42 & 0.40 & +0.13 \\
Free troposphere $(5-7 \mathrm{~km})$ & 0.12 & 0.07 & $<0.01$ & -0.11 \\
\hline
\end{tabular}


posphere. For the free troposphere, the initial values are over 10 times larger than for the calibrated profiles. Values for the calibrated profiles with and without alpha correction show a small difference in the cloud layer (0.02), but larger differences are observed in the free troposphere, where the volume linear depolarization is of the same order of magnitude with the $\alpha$ corrections.

The systematic errors associated with the noncorrected volume depolarization profile are larger in comparison with errors associated with the calibrated, $\alpha$ corrected profile. For noncorrected profiles, errors associated with each instrumental depolarization parameter must be assumed to be large (Bravo-Aranda et al., 2016), e.g., for unknown $\alpha$ values, the associated systematic error should be in the order of $\pm 10^{\circ}$. For known $\alpha$ values the associated systematic error was determined to $\pm 1^{\circ}$. More details on error assessment can be found in Freudenthaler et al. (2009). According to Fig. 8b, the associated error bars show a significant improvement once the calibration and corrections are performed: from 0.1 for the "not corrected data" profile, to 0.06 for the "no $\alpha$ correction" profile and to 0.01 for the "corrected data" profile (for altitudes reaching $8 \mathrm{~km}$ ). A detailed description on the assessment of lidar depolarization uncertainty can be found in Bravo-Aranda et al. (2016).

\subsection{Selected cases of calibrated profiles in the EARLINET framework}

In order to make a first estimate of the depolarization accuracy of the discussed lidar instruments, several experimental results obtained using calibrated depolarization lidar instruments from different EARLINET stations are presented and discussed.

The data show only the corrected depolarization profiles, since many lidar systems provide automatic or hardware corrected depolarization products. Still, the calibrated depolarization products selected for this section use the same calibration techniques as presented in the current study. A comparison between corrected and uncorrected profiles is not required, since the purpose of this section is to give an estimate of the accuracy of depolarization products and to show the importance of calibrated depolarization lidar products in long-range transport studies. The measurements are performed on an extended timescale, so that statistical noise becomes negligible (vertical red delimiters over the rangecorrected signals, RCSs, mark the averaged periods).

Measurements performed using the Granada lidar system (Mulhacen) in July 2012 show the presence of a distinct layer between 2.5 and $5 \mathrm{~km}$ (Fig. 9a-c). The volume linear depolarization ratio shows high values in the aerosol layer $(0.18)$ and levels close to the molecular depolarization in the low aerosol height ranges. The particle depolarization ratio shows values reaching 0.22 in the layer. The back-trajectory model indicates that the corresponding air mass originates in the northern Sahara and was transported for over 5 days over NW
Africa and the Atlantic Ocean (Fig. 9d). According to the back trajectories and the particle linear depolarization values retrieved for these altitudes, the aerosol present in the air mass consists of polluted or mixed mineral dust (Groß et al., 2011).

The RCSs from the Potenza lidar system (MUSA) for August 2012 presents a strong aerosol intrusion above the planetary boundary layer (PBL) (Fig. 10a). The nonhomogeneous layer between 2 and $5 \mathrm{~km}$ has a volume linear depolarization ratio reaching 0.18 and the particle linear depolarization ratio is around 0.31 (Fig. 10b-c), indicating a case of mineral dust. The back-trajectory model shows that the air masses originate from the Sahara regions, having been transported for several days over the desert and the Atlantic Ocean (Fig. 10d).

A detailed analysis including the particle linear depolarization ratio and back trajectories can also provide information regarding not only the nature of the aerosol layers but also the age and purity of aerosol particles (Tesche et al., 2011; Groß et al., 2011; Muller et al., 2003).

The case selected for the Munich lidar system (Maisach) refers to the Eyjafjallajökul volcanic eruption that occurred during April 2010. The range-corrected time series (Fig. 11a) highlight a distinct layer ranging from 2.3 up to $2.8 \mathrm{~km}$. The $1 \mathrm{~h}$ mean value of the particle (volume) linear depolarization ratio measured in this layer is $0.38(0.34)$. The values are consistent with typical values retrieved for fresh volcanic ash (Hervo et al., 2012; Pappalardo et al., 2013). The presence of fresh volcanic ash is also confirmed by the back trajectories: air masses originating from southern Iceland, very close to the Eyjafjallajökul volcano, detected over Munich $48 \mathrm{~h}$ after the eruption (Fig. 11d).

All cases presented in this study were selected to highlight different atmospheric layers and environmental conditions (mineral dust, volcanic ash, ice crystals) and the importance of calibrated depolarization lidar products in aerosol typing. Also, they are used to estimate the depolarization accuracy at $532 \mathrm{~nm}$ for the considered lidar instruments. For low aerosol height ranges, where the impact of the calibration procedures is more obvious, the volume linear depolarization ratio shows values close to the molecular level: $\delta=(0.01-0.03) \pm 0.015$ for all lidar instruments (Behrendt and Nakamura, 2002). Considering that for most cases presented in the study, the low aerosol height ranges are not aerosol free - small amounts of highly depolarizing aerosol could affect the profiles (e.g., ice particles) - it is safe to conclude that, based on the low aerosol height range values, the depolarization accuracy estimate at $532 \mathrm{~nm}$ is better than \pm 0.03 for all presented case studies. This is only an estimate, since for a complete assessment of the lidar accuracy, extended studies are required for each lidar instrument (Freudenthaler, et al., 2016b).

The associated errors were determined by each EARLINET station, according to their own internal error assessment procedures. For most cases, uncertainties related to the 

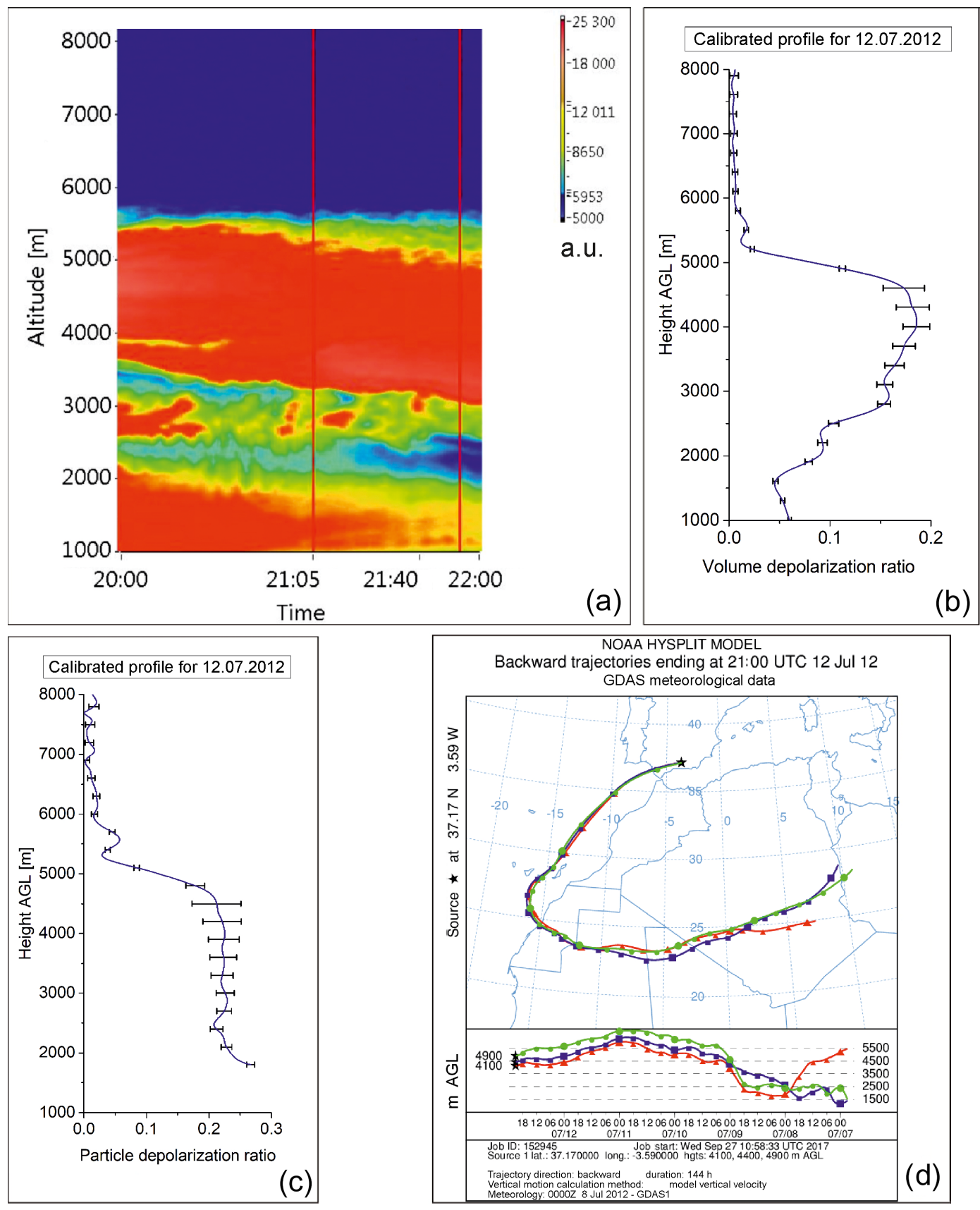

Figure 9. Data from 12 July 2012, at the Mulhacen-Granada lidar system (a) range-corrected time series at $532 \mathrm{~nm}$; (b) volume linear depolarization ratio is a corrected profile at $532 \mathrm{~nm}$ with smoothed data, 45 minutes time average and $45 \mathrm{~m}$ vertical smoothing; (c) particle linear depolarization ratio is a corrected profile at $532 \mathrm{~nm}$ with smoothed data, $45 \mathrm{~min}$ time average and $45 \mathrm{~m}$ vertical smoothing; (d) HYSPLIT back-trajectory analysis $(-144 \mathrm{~h})$ for the detected layers at the Granada site.

systematic errors for the calibrated volume linear depolarization profiles are within $0.01-0.02$ for all heights up to 8 $9 \mathrm{~km}$. The larger uncertainties of the particle linear depolarization profiles with respect to the volume are mainly caused by the backscatter profile, which is required to perform the retrievals. The uncertainties related to the backscatter profiles are the result of additional assumptions required to perform the inversions (especially during daytime) - lidar ratio profile and calibration values (Nemuc et al., 2013; Kovalev and Eichinger, 2004). Although the statistical error is negligible (averaged profiles), statistical and systematic depolarization errors are included for all cases. 

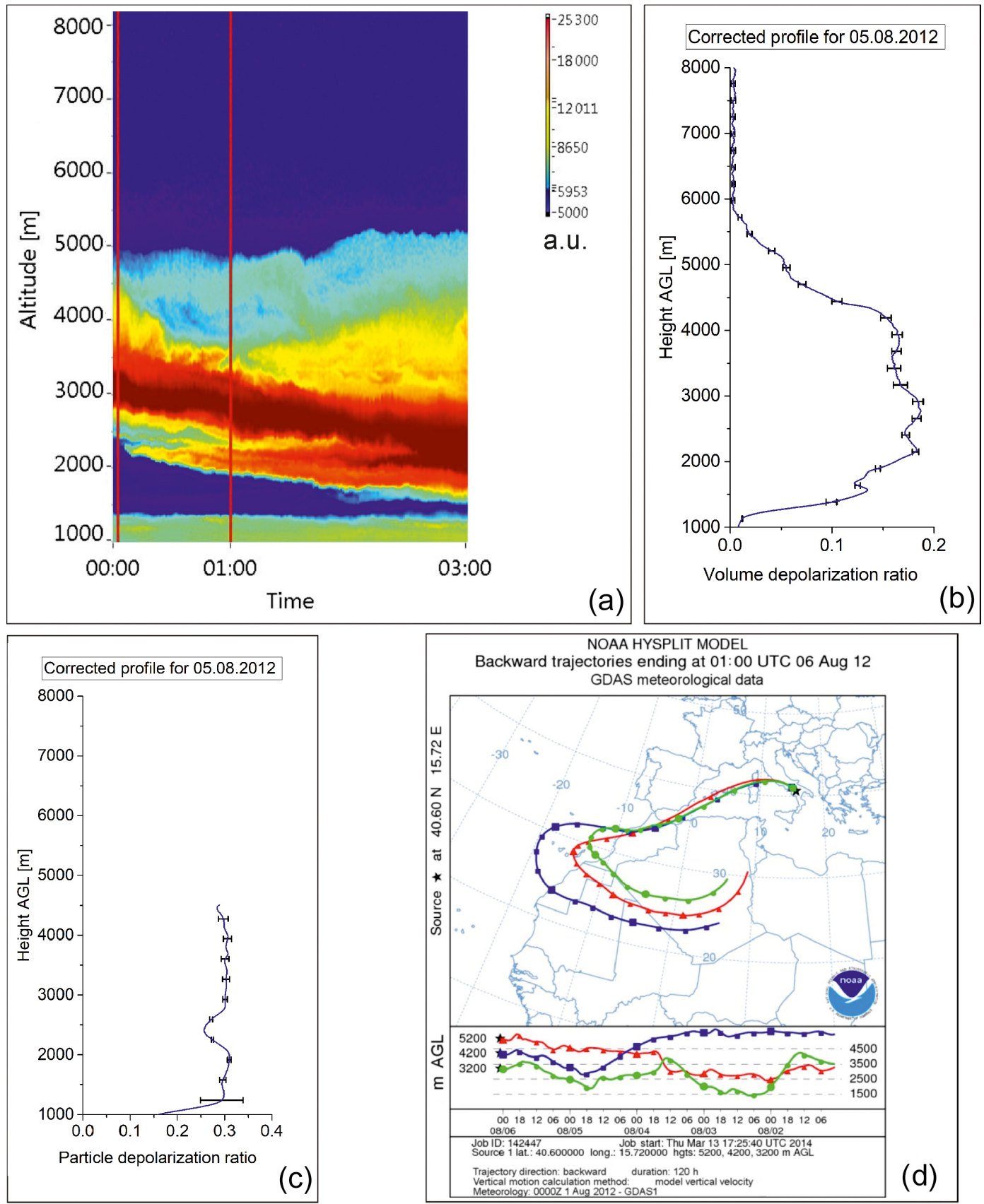

(d)

Figure 10. Data from 5 August 2012, at the MUSA-Potenza lidar system (a) range-corrected time series at $532 \mathrm{~nm}$; (b) volume linear depolarization ratio is a corrected profile at $532 \mathrm{~nm}$ - smoothed data, $1 \mathrm{~h}$ average, $45 \mathrm{~m}$ vertical smoothing; (c) particle linear depolarization ratio is a corrected profile at $532 \mathrm{~nm}$ - smoothed data, $1 \mathrm{~h}$ average, $45 \mathrm{~m}$ vertical smoothing; (d) HYSPLIT back-trajectory analysis ( $-120 \mathrm{~h}$ ) for the detected layers, at the Potenza site.

\section{Conclusions}

This paper presents an extended analysis of various depolarization calibration techniques, specific to depolarization lidar systems within the EARLINET network. The calibration modules were analyzed with respect to two criteria: the type of the calibrator and its placement inside the optical chain.
Different schemes for assessing and correcting the rotation of the plane of polarization of the laser $(\alpha)$ are presented. A method to retrieve the diattenuation of the receiving optics is discussed and analyzed as well.

The two described calibration methods (calibrator in front of the PBS and the calibrator in front of the receiving optics) proved reliable as technical solutions for the $\Delta 90^{\circ}$ cali- 

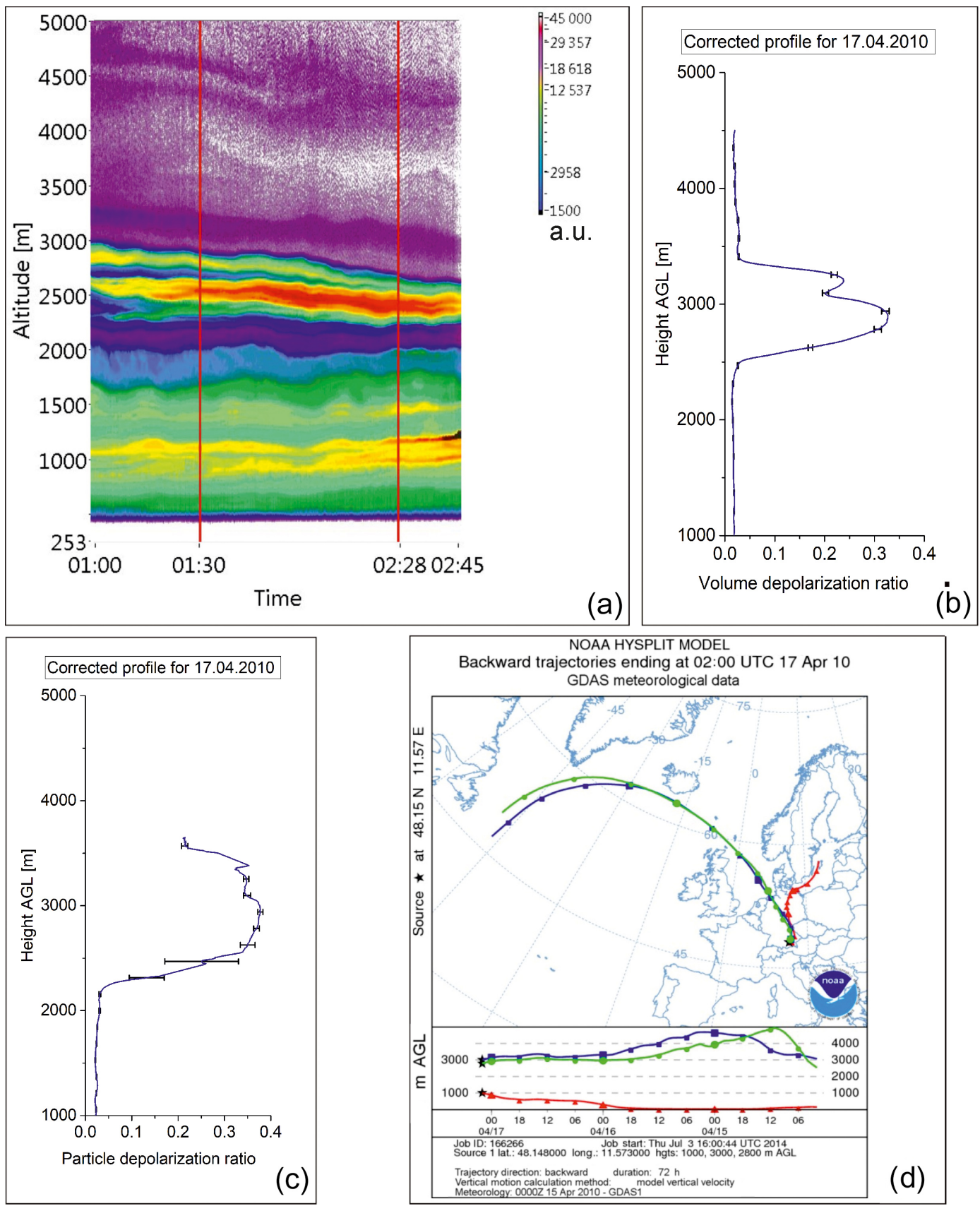

Figure 11. Data from 17 April 2010, at the Maisach-Munich lidar system (a) range-corrected time series at 532 nm; (b) volume linear depolarization ratio is a corrected profile at $532 \mathrm{~nm}$ - smoothed data, $1 \mathrm{~h}$ average, $45 \mathrm{~m}$ vertical smoothing; (c) particle linear depolarization ratio is a corrected profile at $532 \mathrm{~nm}$ - smoothed data, $1 \mathrm{~h}$ average, $45 \mathrm{~m}$ vertical smoothing; (d) HYSPLIT back-trajectory analysis ( $-72 \mathrm{~h}$ ) for the detected layers at the Munich site.

bration. The advantage when using the calibrator in front of the receiving optics is that depolarization products are also corrected for the influence of the receiving optics, while the methods that use the calibrator in front of the PBS take into account only the influence of lidar modules after the calibrator throughout the optical path.
From an experimental point of view, the primary design includes a mechanical rotator for the PBS, a HWP used to rotate the plane of polarization of the collected light and an extra polarizer able to be rotated according to the requirements of the calibration measurements. All calibration designs proved to be effective and the results showed significant improvements after the calibration procedures were ap- 
plied. Among the several calibration schemes described in this study, the $\Delta 90^{\circ} \mathrm{HWP}$ calibrator in front of the receiving optics proved to be the most reliable. The advantages of this type of calibrator can be summarized as follows: it is effective when implementing the calibrator and cost efficient - the extra modules needed to mount the calibrator are cheap and easy to use. The output of the calibrator includes the contribution of the receiving optics, and errors related to the calibrator itself do not influence the measurements, since the modules will be removed after performing the calibration.

The second part of the study was related to the impact of the rotation of the plane of polarization of the laser around the propagation axis with respect to the PBS $(\alpha)$. The effects of $\alpha$ on the final depolarization products and the efficiency of two correction schemes were discussed and analyzed: correction in front of the PBS or in front of the receiver optics by means of a HWP or a mechanical rotator. The efficiency of the second procedure is significantly better, and the errors associated with the correction procedures are much lower than the ones obtained by rotating only the PBS. The drawback of the HWP in front of the receiving optics is related to the limited number of lidar systems it can be applied to. For instruments designed to measure the depolarization using the cross and total channels, the correction of $\alpha$ can also be realized by rotating one optical component inside the receiving unit (linear polarizer).

The experimental determination of the diattenuation parameter of the receiving optics through the combination of two calibration methods has been successfully carried out for several lidar systems, finding a large range of values (from -0.055 to 0.35 ). Since the influence of the diattenuation on the depolarization product is significant, systems in which the calibrator is located in front of the PBS can use this methodology to quantify the diattenuation and then correct for its effect regardless of the calibrator's default position in the optical chain.

The improvements in the depolarization values retrieved for the aerosol layers and ice clouds (where the particle depolarization reaches typical values up to $0.35-0.45 \pm 0.02$ ) as well as in the free troposphere (where the volume linear depolarization shows values around $0.01 \pm 0.01$ ) are visible for calibrated $\left(\eta^{*}\right)$ and corrected $\left(\alpha, D_{\mathrm{O}}, a_{\mathrm{L}}, D_{\mathrm{S}}\right)$ depolarization profiles - Sect. 4.3. These values indicate that for calibrated and corrected signals, the depolarization accuracy at $532 \mathrm{~nm}$ is better than \pm 0.015 . The study also shows how the associated systematic errors are reduced by 1 order of magnitude when proper procedures (corrections and calibration) are applied to the polarization profiles.

All presented case studies show calibrated and corrected depolarization lidar products for selected lidar stations. The calibrated depolarization profiles at $532 \mathrm{~nm}$ show values that fall within a range that is generally accepted in the literature. The study shows that the depolarization accuracy estimate at $532 \mathrm{~nm}$ is better than \pm 0.03 for all presented case studies.
This study emphasizes that the lidar depolarization technique requires adapted calibration and correction procedures according to the lidar system setup to provide homogeneous depolarization products as performed in the EARLINET network.

Data availability. The lidar profiles can be downloaded from the ACTRIS data base at http://actris.nilu.no (Actris/Earlinet, 2018). The lidar simulations and depolarization calibration results can be downloaded from: https://doi.org/10.5281/zenodo.1158435 (Belegante et al., 2018). Any other information is available upon request from the corresponding author. 


\section{Appendix A: Acronyms and shortcuts}

a Polarization parameter of the atmospheric volume

$a_{\mathrm{L}} \quad$ Polarization parameter of the light beam leaving the laser

$\alpha \quad$ Rotation of the plane of polarization of the laser around the propagation axis (laser rotation)

$\beta \quad$ Rotation of the emitter optics around the propagation axis

$\gamma \quad$ Rotation of the receiver optics around the propagation axis

$c_{\varepsilon} \quad \operatorname{Cos}(\varepsilon)$

$s_{\varepsilon} \quad \operatorname{Sin}(\varepsilon)$

$\varepsilon \quad$ Error angle of the $\Delta 90^{\circ}$ calibration setup

$\psi \quad$ Rotation of the calibrator around the light propagation axis

$\delta \quad$ Linear depolarization ration of the atmospheric scattering volume; volume linear depolarization ratio (LDR); real polarization ratio

$\delta^{*} \quad$ Calibrated signal ratio including cross talk and alignment errors; measured depolarization ratio

$\delta^{\mathrm{p}} \quad$ Particle linear depolarization ratio (PDR)

$D \quad$ Diattenuation parameter

$\eta_{\mathrm{T}, \mathrm{R}} \quad$ Electronic amplification of individual transmitted/reflected channels

$\eta \quad$ Calibration factor including only the electronic amplification and the optical diattenuation of the Polarizing beam splitter; real calibration factor

$\eta^{*} \quad$ Measured calibration factor of the polarization channels; the calibration factor including the cross talk from optics before the polarizing beam splitter and from system alignment errors

$\mathbf{M}_{\mathrm{S}} \quad$ Mueller matrix of the polarizing beam splitter

$\mathbf{M}_{\mathrm{T}, \mathrm{R}} \quad$ Mueller matrix in the transmission and reflection path

$T_{\mathrm{S}} \quad$ Transmission of matrix $\mathbf{M}_{\mathrm{S}}$ for unpolarized light

$T^{\mathrm{p}, \mathrm{s}}$

$R^{\mathrm{p}, \mathrm{s}} \quad$ Intensity transmission and reflection coefficients of the polarizing beam splitter for parallel and Perpendicular linearly polarized light with respect to the plane of incidence

F Mueller matrix of the atmospheric scattering volume in backscattering direction

$y \quad$ Optical setup type for the cross and parallel lidar configuration. For $y=-1$ we have the $90^{\circ}$ setup and for $y=1$ we have the $0^{\circ}$ setup (see Fig. 2).

$\Delta \quad$ Differential phase shift of the $\mathrm{p}$ and $\mathrm{s}$ polarized light

$\phi^{\mathrm{p}, \mathrm{s}} \quad$ Phase of the $\mathrm{p}$ and s polarized light 
Competing interests. The authors declare that they have no conflict of interest.

Special issue statement. This article is part of the special issue "EARLINET, the European Aerosol Research Lidar Network". It does not belong to a conference.

Acknowledgements. This work was supported by the European Community's FP7-INFRASTRUCTURES-2010-1 under grant no. 262254 - ACTRIS and by a grant of the STAR-ESA programme 55/2013-CARESSE, Grant from Portuguese Science Foundation (FCT) SFRH/BPD/81132/2011, the Spanish Ministry of Economy and Competitiveness through projects CGL2013-45410-R and CGL2016-81092-R.

Edited by: Albert Ansmann

Reviewed by: three anonymous referees

\section{References}

Althausen, R. E.: PollyNET, a network of multiwavelength polarization Raman lidars, Proc SPIE 2013, https://doi.org/10.1117/12.2028921, 2013.

Alvarez, J. M., Vaughan, M. A., Hostetler, C. A., Hunt, W. H., and Winker, D. M.: Calibration technique for polarization-sensitive lidars, J. Atmos. Ocean. Tech., 23, 683-699, 2006.

Ansmann, A., Bosenberg, J., Chaikovsky, A., Comeron, A., Eckhardt, S., Eixmann, R., Freudenthaler,V., Ginoux, P., Komguem, L., Linne, H., Lopez, M. A., Matthias, V., Mattis, I., Mitev, V., Muller, D., Music, S., Nickovic, S., Pelon, J., Sauvage, L., Sobolewsky, P., Srivastava, M. K., Stohl, A., Torres, O., Vaughn, G., Wandinger, U., and Wiegner, M.: Long-range transport of Saharan dust to Northern Europe: the 11-16 October 2001 outbreak observed with EARLINET, J. Geophys. Res., 108, 4783, https://doi.org/10.1029/2003JD003757, 2003.

Ansmann, A., Seifert, P., Tesche, M., Wandinger, U., Baars, H., Tesche, M., Muller, D., Althausen, D., Engelmann, R., Pauliquevis, T., and Artaxo P.: Dust and smoke transport from Africa to South America: Lidar profiling over Cape Verde and the Amazon rainforest, Geophys. Res. Lett., 36, L11802, https://doi.org/10.1029/2009GL037923, 2009.

ACTRIS/EARLINET: EARLINET aerosol lidar profiles, available at: http://actris.nilu.no, last access: 15 February 2018.

Behrendt, A. and Nakamura, T.: Calculation of the calibration constant of polarization lidar and its dependency on atmospheric temperature, Opt. Express, 10, 805-817, 2002.

Belegante, L., Bravo-Aranda, J. A., Freudenthaler, V., Nicolae, D., Nemuc, A., Ene, D., Alados-Arboledas, L., Amodeo, A., Pappalardo, G., D’Amico, G., Amato, F., Engelmann, R., Baars, H., Wandinger, U., Papayannis, A., Kokkalis, P., and Pereira, S. N.: Data for publication on calibration of lidar depolarization studies - AMT paper (Version 1.0.0), https://doi.org/10.5281/zenodo.1158435, 2018.

Biele, J., Beyerle, G., and Baumgarten, G.: Polarization Lidar: Correction of instrumental effects, Opt. Express, 7, 427-435, 2000.
Bravo-Aranda, J. A., Belegante, L., Freudenthaler, V., AladosArboledas, L., Nicolae, D., Granados-Muñoz, M. J., GuerreroRascado, J. L., Amodeo, A., D’Amico, G., Engelmann, R., Pappalardo, G., Kokkalis, P., Mamouri, R., Papayannis, A., NavasGuzmán, F., Olmo, F. J., Wandinger, U., Amato, F., and Haeffelin, M.: Assessment of lidar depolarization uncertainty by means of a polarimetric lidar simulator, Atmos. Meas. Tech., 9, 49354953, https://doi.org/10.5194/amt-9-4935-2016, 2016.

Bravo-Aranda, J. A., Navas-Guzman, F., Guerrero-Rascado, J. L., Pérez-Ramírez, D., Granados-Munoz, M. J., and Alados-Arboledas, L.: Analysis of lidar depolarization calibration procedure and application to the atmospheric aerosol characterization, Int. J. Remote Sens., 34, 3543-3560, https://doi.org/10.1080/01431161.2012.716546, 2013.

Burton, S. P., Ferrare, R. A., Hostetler, C. A., Hair, J. W., Rogers, R. R., Obland, M. D., Butler, C. F., Cook, A. L., Harper, D. B., and Froyd, K. D.: Aerosol classification using airborne High Spectral Resolution Lidar measurements - methodology and examples, Atmos. Meas. Tech., 5, 73-98, https://doi.org/10.5194/amt-5-732012, 2012.

Chipman, R. A.: Polarimetry, chap. 15, in: Handbook of Optics, vol. I, 3rd edn., McGraw-Hill, 524-562, 2009.

Chipman, R. A.: Mueller matrices, chap. 14, in: Handbook of Optics, vol. I, 3rd edn., McGraw-Hill, 478-541, 2009.

David, G., Miffre, A., Thomas, B., and Rairoux, P.: Sensitive and accurate dual-wavelength UV-VIS polarization detector for optical remote sensing of tropospheric aerosols, Appl. Phys. B, 108, 197-216, https://doi.org/10.1007/s00340-012-5066-x, 2012.

David, G., Thomas, B., Nousiainen, T., Miffre, A., and Rairoux, P.: Retrieving simulated volcanic, desert dust and sea-salt particle properties from two/three-component particle mixtures using UV-VIS polarization lidar and $\mathrm{T}$ matrix, Atmos. Chem. Phys., 13, 6757-6776, https://doi.org/10.5194/acp-136757-2013, 2013.

Draxler, R. R. and Rolph, G. D.: HYSPLIT (HYbrid Single-Particle Lagrangian Integrated Trajectory) Model access via NOAA ARL READY Website (http://ready.arl.noaa.gov/HYSPLIT. php), NOAA Air Resources Laboratory, Silver Spring, MD, 2014.

The EARLINET publishing group 2000-2010, Adam, M., Alados-Arboledas, L., Althausen, D., Amiridis, V., Amodeo, A., Ansmann, A., Apituley, A., Arshinov, Y., Balis, D., Belegante, L., Bobrovnikov, S., Boselli, A., Bravo-Aranda, J. A., Bosenberg, J., Carstea, E., Chaikovsky, A., Comeron, A., D’Amico, G., Daou, D., Dreischuh, T., Engelmann, R., Finger, F., Freudenthaler, V., Garcia-Vizcaino, D., Garcia, A. J. F., Geiss, A., Giannakaki, E., Giehl, H., Giunta, A., De Graaf, M., Granados-Munoz, M. J., Grein, M., Grigorov, I., Gross, S., Gruening, C., Guerrero-Rascado, J. L., Haeffelin, M., Hayek, T., Iarlori, M., Kanitz, T., Kokkalis, P., Linne, H., Madonna, F., Mamouriat, R.-E., Matthias, V., Mattis, I., Menendez, F. M., Mitev, V., Mona, L., Morille, Y., Munoz, C., Muller, A., Muller, D., Navas-Guzman, F., Nemuc, A., Nicolae, D., Pandolfi, M., Papayannis, A., Pappalardo, G., Pelon, J., Perrone, M. R., Pietruczuk, A., Pisani, G., Potma, C., Preissler, J., Pujadas, M., Putaud, J., Radu, C., Ravetta, F., Reigert, A., Rizi, V., Rocadenbosch, F., Rodriguez, A., Sauvage, L., Schmidt, J., Schnell, F., Schwarz, A., Seifert, P., Serikov, I., Sicard, M., Silva, A. M., Simeonov, V., Siomos, N., Sirch, T., Spinelli, N., 
Stoyanov, D., Talianu, C., Tesche, M., De Tomasi, F., Trickl, T., Vaughan, G., Volten, H., Wagner, F., Wandinger, U., Wang, X., Wiegner, M., and Wilson, K. M.: EARLINET all observations (2000-2010), World Data Centre for Climate (WDCC), https://doi.org/10.1594/WDCC/EN_all_measurements_20002010, 2014a.

The EARLINET publishing group 2000-2010, Adam, M., Alados-Arboledas, L., Althausen, D., Amiridis, V., Amodeo, A., Ansmann, A., Apituley, A., Arshinov, Y., Balis, D., Belegante, L., Bobrovnikov, S., Boselli, A., Bravo-Aranda, J. A., Bosenberg, J., Carstea, E., Chaikovsky, A., Comeron, A., D’Amico, G., Daou, D., Dreischuh, T., Engelmann, R., Finger, F., Freudenthaler, V., Garcia-Vizcaino, D., Garcia, A. J. F., Geiss, A., Giannakaki, E., Giehl, H., Giunta, A., De Graaf, M., Granados-Munoz, M. J., Grein, M., Grigorov, I., Gross, S., Gruening, C., Guerrero-Rascado, J. L., Haeffelin, M., Hayek, T., Iarlori, M., Kanitz, T., Kokkalis, P., Linne, H., Madonna, F., Mamouriat, R.-E., Matthias, V., Mattis, I., Menendez, F. M., Mitev, V., Mona, L., Morille, Y., Munoz, C., Muller, A., Muller, D., Navas-Guzman, F., Nemuc, A., Nicolae, D., Pandolfi, M., Papayannis, A., Pappalardo, G., Pelon, J., Perrone, M. R., Pietruczuk, A., Pisani, G., Potma, C., Preissler, J., Pujadas, M., Putaud, J., Radu, C., Ravetta, F., Reigert, A., Rizi, V., Rocadenbosch, F., Rodriguez, A., Sauvage, L., Schmidt, J., Schnell, F., Schwarz, A., Seifert, P., Serikov, I., Sicard, M., Silva, A. M., Simeonov, V., Siomos, N., Sirch, T., Spinelli, N., Stoyanov, D., Talianu, C., Tesche, M., De Tomasi, F., Trickl, T., Vaughan, G., Volten, H., Wagner, F., Wandinger, U., Wang, X., Wiegner, M. and Wilson, K. M.: EARLINET climatology (2000-2010), World Data Centre for Climate, https://doi.org/10.1594/WDCC/EN_Climatology_2000-2010, 2014b.

The EARLINET publishing group 2000-2010, Adam, M., Alados-Arboledas, L., Althausen, D., Amiridis, V., Amodeo, A., Ansmann, A., Apituley, A., Arshinov, Y., Balis, D., Belegante, L., Bobrovnikov, S., Boselli, A., Bravo-Aranda, J. A., Bosenberg, J., Carstea, E., Chaikovsky, A., Comeron, A., D’Amico, G., Daou, D., Dreischuh, T., Engelmann, R., Finger, F., Freudenthaler, V., Garcia-Vizcaino, D., Garcia, A. J. F., Geiss, A., Giannakaki, E., Giehl, H., Giunta, A., De Graaf, M., Granados-Munoz, M. J., Grein, M., Grigorov, I., Gross, S., Gruening, C., Guerrero-Rascado, J. L., Haeffelin, M., Hayek, T., Iarlori, M., Kanitz, T., Kokkalis, P., Linne, H., Madonna, F., Mamouriat, R.-E., Matthias, V., Mattis, I., Menendez, F. M., Mitev, V., Mona, L., Morille, Y., Munoz, C., Muller, A., Muller, D., Navas-Guzman, F., Nemuc, A., Nicolae, D., Pandolfi, M., Papayannis, A., Pappalardo, G., Pelon, J., Perrone, M. R., Pietruczuk, A., Pisani, G., Potma, C., Preissler, J., Pujadas, M., Putaud, J., Radu, C., Ravetta, F., Reigert, A., Rizi, V., Rocadenbosch, F., Rodriguez, A., Sauvage, L., Schmidt, J., Schnell, F., Schwarz, A., Seifert, P., Serikov, I., Sicard, M., Silva, A. M., Simeonov, V., Siomos, N., Sirch, T., Spinelli, N., Stoyanov, D., Talianu, C., Tesche, M., De Tomasi, F., Trickl, T., Vaughan, G., Volten, H., Wagner, F., Wandinger, U., Wang, X., Wiegner, M. and Wilson, K. M.: EARLINET observations related to Saharan Dust events (2000-2010), World Data Centre for Climate, https://doi.org/10.1594/WDCC/EARLINET_SaharanDust_20002010, 2014d.
The EARLINET publishing group 2000-2010, Adam, M., Alados-Arboledas, L., Althausen, D., Amiridis, V., Amodeo, A., Ansmann, A., Apituley, A., Arshinov, Y., Balis, D., Belegante, L., Bobrovnikov, S., Boselli, A., Bravo-Aranda, J. A., Bosenberg, J., Carstea, E., Chaikovsky, A., Comeron, A., D’Amico, G., Daou, D., Dreischuh, T., Engelmann, R., Finger, F., Freudenthaler, V., Garcia-Vizcaino, D., Garcia, A. J. F., Geiss, A., Giannakaki, E., Giehl, H., Giunta, A., De Graaf, M., Granados-Munoz, M. J., Grein, M., Grigorov, I., Gross, S., Gruening, C., Guerrero-Rascado, J. L., Haeffelin, M., Hayek, T., Iarlori, M., Kanitz, T., Kokkalis, P., Linne, H., Madonna, F., Mamouriat, R.-E., Matthias, V., Mattis, I., Menendez, F. M., Mitev, V., Mona, L., Morille, Y., Munoz, C., Muller, A., Muller, D., Navas-Guzman, F., Nemuc, A., Nicolae, D., Pandolfi, M., Papayannis, A., Pappalardo, G., Pelon, J., Perrone, M. R., Pietruczuk, A., Pisani, G., Potma, C., Preissler, J., Pujadas, M., Putaud, J., Radu, C., Ravetta, F., Reigert, A., Rizi, V., Rocadenbosch, F., Rodriguez, A., Sauvage, L., Schmidt, J., Schnell, F., Schwarz, A., Seifert, P., Serikov, I., Sicard, M., Silva, A. M., Simeonov, V., Siomos, N., Sirch, T., Spinelli, N., Stoyanov, D., Talianu, C., Tesche, M., De Tomasi, F., Trickl, T., Vaughan, G., Volten, H., Wagner, F., Wandinger, U., Wang, X., Wiegner, M., and Wilson, K. M.: EARLINET observations related to volcanic eruptions (2000-2010), World Data Centre for Climate, https://doi.org/10.1594/WDCC/EN_VolcanicEruption_20002010, 2014e.

Engelmann, R., Kanitz, T., Baars, H., Heese, B., Althausen, D., Skupin, A., Wandinger, U., Komppula, M., Stachlewska, I. S., Amiridis, V., Marinou, E., Mattis, I., Linné, H., and Ansmann, A.: The automated multiwavelength Raman polarization and water-vapor lidar PollyXT: the neXT generation, Atmos. Meas. Tech., 9, 1767-1784, https://doi.org/10.5194/amt-9-1767-2016, 2016.

Fernald, F. G., Herman, B. M., and Reagan, J. A.: Determination of Aerosol height distributions by Lidar, J. Appl. Meteorol., 11, 482-489, 1972.

Freudenthaler, V., Esselborn, M., Wiegner, M., Heese, B., Tesche, M., Ansmann, A., Muller, D., Althausen, D., Wirth, M., Andreas, F. I. X., Ehret, G., Knippertz, P., Toledano, C., Gasteiger, J., Garhammer, M., and Seefeldner, M.: Depolarization ratio profiling at several wavelengths in pure saharan dust during SAMUM 2006, Tellus B, 61, 165-179, 2009.

Freudenthaler, V.: About the effects of polarising optics on lidar signals and the $\triangle 90$ calibration, Atmos. Meas. Tech., 9, 41814255, https://doi.org/10.5194/amt-9-4181-2016, 2016.

Freudenthaler, V., Seefeldner, M., Gross, S., and Wandinger, U.: Accuracy of linear depolarization ratios in clean air ranges measured with POLIS-6 at 355 and 532 nm, EPJ Web of Conferences, EDP Sciences, vol. 119, 25013, 2016.

Garcia-Caurel, E., Ossikovski, R., Foldyna, M., Pierangelo, A., Drévillon, B., and De Martino, A.: Advanced Mueller Ellipsometry Instrumentation and Data Analysis, in Ellipsometry at the Nanoscale, edited by: Losurdo, M. and Hingerl, K., 31-143, Springer Berlin Heidelberg, Berlin, Heidelberg., 2013.

Gasteiger, J. and Freudenthaler, V.: Benefit of depolarization ratio at $\lambda=1064 \mathrm{~nm}$ for the retrieval of the aerosol microphysics from lidar measurements, Atmos. Meas. Tech., 7, 3773-3781, https://doi.org/10.5194/amt-7-3773-2014, 2014. 
Groß, S., Freudenthaler, V., Schepanski, K., Toledano, C., Schäfler, A., Ansmann, A., and Weinzierl, B.: Optical properties of long-range transported Saharan dust over Barbados as measured by dual-wavelength depolarization Raman lidar measurements, Atmos. Chem. Phys., 15, 11067-11080, https://doi.org/10.5194/acp-15-11067-2015, 2015.

Groß, S., Esselborn, M., Weinzierl, B., Wirth, M., Fix, A., and Petzold, A.: Aerosol classification by airborne high spectral resolution lidar observations, Atmos. Chem. Phys., 13, 2487-2505, https://doi.org/10.5194/acp-13-2487-2013, 2013.

Groß, S., Tesche, M., Freudenthaler, V., Toledano, C., Wiegner, M., Ansmann, A., Althausen, D., and Seefeldner, M.: Characterization of Saharan dust, marine aerosols and mixtures of biomassburning aerosols and dust by means of multi-wavelength depolarization and Raman lidar measurements during SAMUM 2, Tellus B, 63, 706-724, 2011.

Guzman, F. N., Bravo-Aranda, J. A., Guerrero-Rascado, J. L., Granados-Munoz, M. J., and Arboledas, L. A.: Statistical analysis of aerosol optical properties retrieved by Raman lidar over Southeastern Spain, Tellus B, 65, https://doi.org/10.3402/tellusb.v65i0.21234, 2013.

Hervo, M., Quennehen, B., Kristiansen, N. I., Boulon, J., Stohl, A., Fréville, P., Pichon, J.-M., Picard, D., Labazuy, P., Gouhier, M., Roger, J.-C., Colomb, A., Schwarzenboeck, A., and Sellegri, K.: Physical and optical properties of 2010 Eyjafjallajökull volcanic eruption aerosol: ground-based, Lidar and airborne measurements in France, Atmos. Chem. Phys., 12, 17211736, https://doi.org/10.5194/acp-12-1721-2012, 2012.

Janicka, L., Stachlewska, I. S., Veselovskii, I., and Baars, H.: Temporal variations in optical and microphysical properties of mineral dust and biomass burning aerosol derived from daytime Raman lidar observations over Warsaw, Poland, Atmos. Environ., 169, 162-174, https://doi.org/10.1016/j.atmosenv.2017.09.022, 2017.

Klett, J. D.: Lidar inversion with variable backscatter/extinction ratios, Appl. Opt., 24, 1638, https://doi.org/10.1364/AO.24.001638, 1985.

Klett, J. D.: Stable Analytical Inversion Solution For Processing Lidar Returns, Appl. Opt., 20, 211-220, 1981.

Kokkalis, P., Papayannis, A., Amiridis, V., Mamouri, R. E., Veselovskii, I., Kolgotin, A., Tsaknakis, G., Kristiansen, N. I., Stohl, A., and Mona, L.: Optical, microphysical, mass and geometrical properties of aged volcanic particles observed over Athens, Greece, during the Eyjafjallajökull eruption in April 2010 through synergy of Raman lidar and sunphotometer measurements, Atmos. Chem. Phys., 13, 9303-9320, https://doi.org/10.5194/acp-13-9303-2013, 2013.

Kovalev, V. and Eichinger, V.: Elastic lidar: Theory, Practice and Analysis Methods, Wiley Interscience Publ., New York, USA, 2004

Lu, S.-Y. and Chipman, R. A.: Interpretation of Mueller matrices based on polar decomposition, J. Opt. Soc. Am. A, 13, 11061113, 1996.

Madonna, F., Amodeo, A., Boselli, A., Cornacchia, C., Cuomo, V., D’Amico, G., Giunta, A., Mona, L., and Pappalardo, G.: CIAO: the CNR-IMAA advanced observatory for atmospheric research, Atmos. Meas. Tech., 4, 1191-1208, https://doi.org/10.5194/amt4-1191-2011, 2011.
Mamouri, R. E., Papayannis, A., Amiridis, V., Müller, D., Kokkalis, P., Rapsomanikis, S., Karageorgos, E. T., Tsaknakis, G., Nenes, A., Kazadzis, S., and Remoundaki, E.: Multi-wavelength Raman lidar, sun photometric and aircraft measurements in combination with inversion models for the estimation of the aerosol optical and physico-chemical properties over Athens, Greece, Atmos. Meas. Tech., 5, 1793-1808, https://doi.org/10.5194/amt-5-17932012, 2012.

Mattis, I., Tesche, M., Grein, M., Freudenthaler, V., and Muller, D.: "Systematic error of lidar profiles caused by a polarizationdependent receiver transmission: quantification and error correction scheme", Appl. Opt., 48, 2742-2751, 2009.

Measures R. M.: Laser Remote Sensing. Fundamentals and Applications, Krieger Publishing Company, Malabar, Florida, USA, 1992.

Mona, L., Liu, Z., and Muller, D.: Lidar Measurements for Desert Dust Characterization: An Overview, Adv. Meteorol., ID356265, https://doi.org/10.1155/2012/356265, 2012.

Mortier, A., Goloub, P., Podvin, T., Deroo, C., Chaikovsky, A., Ajtai, N., Blarel, L., Tanre, D., and Derimian, Y.: Detection and characterization of volcanic ash plumes over Lille during the Eyjafjallajökull eruption, Atmos. Chem. Phys., 13, 3705-3720, https://doi.org/10.5194/acp-13-3705-2013, 2013.

Muller, D., Mattis, I., Wandinger, U., Ansmann, A., Althausen, D., Dubovik, O., Eckhardt, S., and Stohl, A., Saharan dust over a central European EARLINET-AERONET site: Combined observations with Raman lidar and Sun photometer, J. Geophys. Res., 108, 4345, https://doi.org/10.1029/2002JD002918, 2003.

Nemuc, A., Vasilescu, J., Talianu, C., Belegante, L., and Nicolae, D.: Assessment of aerosol's mass concentrations from measured linear particle depolarization ratio (vertically resolved) and simulations, Atmos. Meas. Tech., 6, 3243-3255, https://doi.org/10.5194/amt-6-3243-2013, 2013.

Nicolae, D., Nemuc, A., Muller, D., Talianu, C., Vasilescu, J., Belegante, L., and Kolgotin, A.: Characterization of fresh and aged biomass burning events using multiwavelength Raman lidar and mass spectrometry, J. Geophys. Res. Atmos., 118, https://doi.org/10.1002/jgrd.50324, 2013.

Ossikovski, R.: Alternative depolarization criteria for Mueller matrices, J. Opt. Soc. Am. A., 27, 808-814, 2010.

Papayannis, A., Amiridis, V., Mona, L., Tsaknakis, G., Balis, D., Bosenberg, J., Tchaikovsky, A., De Tomasi, F., Grigorov, I., Mattis, I., Mitev, V., Muller D., Nickovic, S., Perez, C., Pietruczuk, A., Pisani, G., Ravetta, F., Rizi, V., Sicard, M., Trickl, T., Wiegner, M., Gerding, M., Mamouri, R. E., D’Amico, G., and Pappalardo, G.: Systematic lidar observations of Saharan dust over Europe in the frame of EARLINET (2000-2002), J. Geophys. Res., https://doi.org/10.1029/2007JD009028, 2008.

Pappalardo, G., Amodeo, A., Apituley, A., Comeron, A., Freudenthaler, V., Linné, H., Ansmann, A., Bösenberg, J., D’Amico, G., Mattis, I., Mona, L., Wandinger, U., Amiridis, V., AladosArboledas, L., Nicolae, D., and Wiegner, M.: EARLINET: towards an advanced sustainable European aerosol lidar network, Atmos. Meas. Tech., 7, 2389-2409, https://doi.org/10.5194/amt7-2389-2014, 2014.

Pappalardo, G., Mona, L., D’Amico, G., Wandinger, U., Adam, M., Amodeo, A., Ansmann, A., Apituley, A., Alados Arboledas, L., Balis, D., Boselli, A., Bravo-Aranda, J. A., Chaikovsky, A., Comeron, A., Cuesta, J., De Tomasi, F., Freudenthaler, V., Gausa, 
M., Giannakaki, E., Giehl, H., Giunta, A., Grigorov, I., Groß, S., Haeffelin, M., Hiebsch, A., Iarlori, M., Lange, D., Linné, H., Madonna, F., Mattis, I., Mamouri, R.-E., McAuliffe, M. A. P., Mitev, V., Molero, F., Navas-Guzman, F., Nicolae, D., Papayannis, A., Perrone, M. R., Pietras, C., Pietruczuk, A., Pisani, G., Preißler, J., Pujadas, M., Rizi, V., Ruth, A. A., Schmidt, J., Schnell, F., Seifert, P., Serikov, I., Sicard, M., Simeonov, V., Spinelli, N., Stebel, K., Tesche, M., Trickl, T., Wang, X., Wagner, F., Wiegner, M., and Wilson, K. M.: Four-dimensional distribution of the 2010 Eyjafjallajökull volcanic cloud over Europe observed by EARLINET, Atmos. Chem. Phys., 13, 4429-4450, https://doi.org/10.5194/acp-13-4429-2013, 2013.

Petzold, A., Esselborn, M., Weinzierl, B., Ehret, G., Ansmann, A., Müller, D., Donovan, D., Zadelhoff, G.-J., Berthier, S., Wiegner, M., Gasteiger, J., Buras-Schnell, R., Mayer, B., Lajas, D. and Wehr, T.: ICAROHS - Inter-Comparison of Aerosol Retrievals and Observational Requirements for Multi-wavelength HSRL Systems., Report, 101, ISBN, ESA Contract No. 22169/NL/CT, 2010.

Reichardt, J., Baumgart, R., and McGee, T. J.: Threesignal method for accurate measurements of depolarization ratio with lidar, Appl. Opt., 42, 4909-4913, https://doi.org/10.1364/AO.42.004909, 2003.

Rolph, G. D.: Real-time Environmental Applications and Display sYstem (READY) Website, NOAA Air Resources Laboratory, Silver Spring, MD, available at: http://ready.arl.noaa.gov, 2014.

Sassen, K.: Polarization in Lidar, in: Lidar, edited by: Weitkamp, C., Springer Press, New York, 19-42, 2005.
Sassen, K., Zhu, J., Webley, P., Dean, K., and Cobb, P., Volcanic ash plume identification using polarization lidar: $\mathrm{Au}-$ gustine eruption, Alaska, Geophys. Res. Lett., 34, L08803, https://doi.org/10.1029/2006GL027237, 2007.

Snels, M., Cairo, F., Colao, F., and Di Donfrancesco, G.: Calibration method for depolarization lidar measurements, Int. J. Remote Sens., 30, 5725-5736, 2009.

Stocker, T. F., Qin, D., Plattner, G.-K., Tignor, M., Allen, S. K., Boschung, J., Nauels, A., Xia, Y., Bex, B., and Midgley, B. M.: IPCC: climate change 2013: the physical science basis. Contribution of working group I to the fifth assessment report of the intergovernmental panel on climate change, Cambridge University Press., 2013.

Tesche, M., Gross, S., Ansmann, A., Muller, D., Althausen, D., Freudenthaler, V., and Esselborn, M., Profiling of Saharan dust and biomass-burning smoke with multiwavelength polarization Raman lidar at Cape Verde, Tellus B, 63, 649-676, 2011.

Timofte, A., Belegante, L., Cazacu, M. M., Albina, B., Talianu, C., and Gurlui, S.: Study of planetary boundary layer height from LIDAR measurements and ALARO model, J. Optoelectron. Adv. M., 17, 911-917, 2015.

Winker, D. M., Hunt, W. H., and McGill, M. J.: Initial performance assessment of CALIOP, Geophys. Res. Lett., 34, L19803, https://doi.org/10.1029/2007GL030135, 2007. 